Check for updates

Cite this: J. Mater. Chem. A, 2018, 6, 23587

Received 28th June 2018 Accepted 28th September 2018

DOI: $10.1039 / c 8 t a 06224 b$

rsc.li/materials-a

\section{Synthesis and functionalisation of spherical meso-, hybrid meso/macro- and macro-porous cellular silica foam materials with regulated pore sizes for $\mathrm{CO}_{2}$ capture $\dagger$}

\author{
Yuan Sun, (D) ${ }^{a}$ Xin Liu, (DD ${ }^{a}$ Chenggong Sun, (D) *a Waleed Al-Sarraf, ${ }^{a}$ Khai Zhen Foo, ${ }^{a}$ \\ Yang Meng, ${ }^{a}$ Stevens Lee, ${ }^{a}$ Wenlong Wang ${ }^{\mathrm{b}}$ and Hao Liu (D) ${ }^{a}$
}

\begin{abstract}
A variety of meso, meso/macro and macro-structured siliceous cellular foam (SCF) materials have been tailor-designed and fabricated using a modified microemulsion templating methodology with trimethyl benzene (TMB) as the pore expander and Pluronic ${ }^{T M}$ block co-polymer (P123) as the surfactant for preparing polyethyleneimine (PEI)-impregnated adsorbents for $\mathrm{CO}_{2}$ capture. The effect of preparation conditions, such as the TMB/P123 mass ratio, aging temperature and aging time, on the SCF morphology and pore structures and hence on the $\mathrm{CO}_{2}$ adsorption performance of the PEI-modified SCF adsorbents was investigated comprehensively. BET measurements and morphological characterisation with SEM revealed that the SCF materials prepared using lower TMB/P123 ratios ( $\leq 1)$ and aging temperatures $\left(\leq 100^{\circ} \mathrm{C}\right)$ were typically meso-structured with relatively lower cell wall thicknesses but increasing the TMB/P123 ratio, aging temperature and aging times led to a transformation of the SCFs from being meso-structured into hybrid meso/macro or even purely macro-structured nano-cellular materials with increased wall thicknesses, pore volumes and window sizes. $\mathrm{CO}_{2}$ adsorption characterisation of the PEIimpregnated SCFs demonstrated that while all the SCF materials exhibited higher capacities and faster adsorption kinetics compared to conventional meso-structured siliceous materials, the hybrid meso/ macro and macro-structured SCF substrates were found to have the best $\mathrm{CO}_{2}$ adsorption performance, with uptake capacities reaching $180.2 \mathrm{mg}-\mathrm{CO}_{2}$ per g-adsorbent $(5.85 \mathrm{mmol}$ per g-PEI) for PEI-600 impregnation and $198.2 \mathrm{mg}-\mathrm{CO}_{2}$ per g-adsorbent ( $6.44 \mathrm{mmol}$ per $\mathrm{g}$-amine) for the hybrid impregnation of PEI-600-TEPA at $75{ }^{\circ} \mathrm{C}$ and 0.15 bar $\mathrm{CO}_{2}$, which are significantly higher than those previously reported under similar conditions. The macro- and hybrid meso/macro-structured SCF materials were found to be particularly suitable for preparing high molecular weight PEI-modified adsorbents for greatly improved thermo-stability. At 60 wt\% PEl loading, the $\mathrm{CO}_{2}$ capacity reached 126 and $97.3 \mathrm{mg}-\mathrm{CO}_{2}$ per g-ads for PEI-10 000 and PEI-60 000, respectively, both showing extraordinary lifetime performance. Differing from previous findings, no particularly favourable pore diameters or window sizes for PEI impregnation are observed for the wide range of SCF materials examined, although close to linear relationships between the $\mathrm{CO}_{2}$ uptake capacity and total pore volume appear to exist for the SCF materials with pore volumes below $2.2 \mathrm{~cm}^{3} \mathrm{~g}^{-1}$ and pore diameters/window sizes $\leq 28 \mathrm{~nm}$.
\end{abstract}

\section{Introduction}

Carbon capture and storage (CCS) has widely been recognised as being a crucial part of worldwide low carbon energy portfolios required to meet the target of global climate change without compromising energy security, given the projected soaring

${ }^{a}$ Faculty of Engineering, University of Nottingham, University Park, Nottingham NG7 2RD, UK. E-mail: cheng-gong.sun@nottingham.ac.uk

${ }^{b}$ School of Energy and Power Engineering, Shandong University, Jinan, Shandong 250061, P. R. China

$\dagger$ Electronic supplementary information (ESI) available. See DOI: $10.1039 / \mathrm{c} 8 \mathrm{ta} 06224 \mathrm{~b}$ energy demand and the continual dominance of fossil energy in the worldwide energy landscape. ${ }^{\mathbf{1 - 4}}$ However, the successful development and deployment of enabling capture technologies hold the key to the overall success of CCS as carbon capture represents the most costly single element of the whole CCS chain, which goes from $\mathrm{CO}_{2}$ capture through compression and transport to geological storage. At present, aqueous amine scrubbing in its various forms is the state-of-art capture technology for use, but the high energy penalty together with a range of environmental and operational issues (e.g. solvent degradation, equipment corrosion and toxic and corrosive emissions) has become the major challenge for the large scale deployment 
of this technology for CCS. ${ }^{5}$ It has been estimated that postcombustion capture (PCC) with aqueous amine scrubbing could increase the cost of power generation by $32 \%$ and $65 \%$ for gas and coal-fired power plants, respectively. Consequently, the development of alternative cost-effective PCC technologies has received tremendous attention over recent years, with the adsorption-based solid adsorbent looping technology having become the persistent focus of many investigations due to the potentially significantly reduced energy penalty and the choice of a wide range of candidate adsorbent materials, including but not limited to zeolites, ${ }^{6,7}$ immobilized amines, ${ }^{\mathbf{8}, 9}$ activated carbons, ${ }^{10,11}$ metal-organic frameworks (MOFs), ${ }^{12,13}$ covalentorganic frameworks (COFs) ${ }^{\mathbf{1 4 , 1 5}}$ and zeolitic imidazolate frameworks. ${ }^{16,17}$ Among the candidate sorbent materials, immobilized amines possess many desirable $\mathrm{CO}_{2}$ adsorptive properties that may not be easily obtained with other sorbent materials, such as their extremely high $\mathrm{CO}_{2}$ selectivity, fast adsorption kinetics and high adsorption capacity especially at very low $\mathrm{CO}_{2}$ partial pressures, great moisture tolerance and favourable operating temperature window of $50-80{ }^{\circ} \mathrm{C}$ that minimizes or essentially eliminates the cooling need of typical flue gas streams from power plants. ${ }^{18-23}$

The $\mathrm{CO}_{2}$ adsorption of immobilised amine adsorbents follows similar reaction mechanisms to those in the aqueous amine absorption process, which involves the reversible formation of ammonium carbamate under anhydrous flue gas conditions and ammonium bicarbonate under wet conditions. Two typical preparation methodologies are used, namely surface grafting and direct impregnation. In general, aminegrafted silica sorbents benefit from improved amine efficiency and thermal stability but usually suffer from low amine loadings due to the limited density of accessible surface silanol groups, giving rise to $\mathrm{CO}_{2}$ adsorption capacities being generally well below $3 \mathrm{mmol} \mathrm{CO}_{2}$ per $\mathrm{g}$ sorbent (hereinafter abbreviated to $\mathrm{mmol} \mathrm{g}^{-1}$ ) or $13.2 \mathrm{wt} \%$. The highest adsorption capacity of $\mathrm{ca} .4$ $\mathrm{mmol} \mathrm{g}{ }^{-1}(17.6 \mathrm{wt} \%)$ was obtained by Drese et al. ${ }^{24}$ at $75{ }^{\circ} \mathrm{C}$ in $10 \% \mathrm{CO}_{2} / \mathrm{N}_{2}$ for a hyperbranched aminosilica with a grafted amine loading of $9.78 \mathrm{mmol}$ amine per $\mathrm{g}$ SBA-15, whereas threedimensional macro-porous silica with a grafted amine density of $10.98 \mathrm{mmol} \mathrm{N}$ per $\mathrm{g}$ could only achieve a maximum $\mathrm{CO}_{2}$ capacity of $2.76 \mathrm{mmol} \mathrm{g}^{-1}$ under similar conditions. ${ }^{25}$ In comparison, impregnation as a more convenient and less corrosive preparation methodology can achieve much larger amine loading capacity but the produced sorbents may suffer from the potential evaporation loss of the impregnated amines, an issue that can be improved by using higher boiling amines. ${ }^{26}$ Builes and Vega $^{27}$ compared the performance of immobilised amines prepared from different methodologies and found that compared to grafting, impregnation persistently gives rise to significantly higher adsorption capacities particularly at low $\mathrm{CO}_{2}$ partial pressures, due to the mobility of the functionalised amine chains that leads to the formation of microporosity-like micro-cavities inside the bulk phase of the impregnated amines. In contrast, similar structures cannot be formed within the densely grafted amine groups and this can limit the potential of achieving higher adsorption capacities by increasing the grafting density.
Numerous investigations have shown that for both impregnation and grafting, the performance of supported amine sorbents is not only determined by the chemical nature of the amines but also by the type of porous solid support, with mesoporous silica materials such as MCM-41, MCM-42, MCM48, SBA-15, SBA-16 and hexagonal mesoporous silica (HMS) being the most widely used solid supports because of their tuneable structures and re-addressable surface chemistries. Son et $a .^{28}$ studied the $\mathrm{CO}_{2}$ adsorptive properties of different mesoporous silica materials at the same maximum PEI loading of $50 \mathrm{wt} \%$ and found that dictated by the average pore diameter of the solid support, the $\mathrm{CO}_{2}$ uptake of PEI-modified silica sorbent follows the order of KIT- $6>$ SBA-16 $\approx$ SBA-15 $>$ MCM-48 $>$ MCM41, with the capacities varying from $2.5 \mathrm{mmol} \mathrm{g}^{-1}$ for MCM-41 with a 1-dimensional (1D) pore diameter of $2.8 \mathrm{~nm}$ to $3.1 \mathrm{mmol} \mathrm{g}^{-1}$ for KIT- 6 with a 3D pore diameter of $6.5 \mathrm{~nm}$. Over recent years, many efforts have been made to expand the pore diameter or increase the pore volume of mesostructured silica supports to increase the amine loading and hence $\mathrm{CO}_{2}$ uptake capacity. It has been found that regardless the preparation techniques employed, the immobilised amine sorbents prepared using pore-expanded MCM-41, ${ }^{29-32}$ MCM-48, ${ }^{29}$ SBA-15 ${ }^{29-32}$ and $\mathrm{HMS}^{33,34}$ all showed considerably higher $\mathrm{CO}_{2}$ adsorption capacities than their pore-unexpanded counterparts. In addition to the pore size and volume, the length of pore channels of support materials also appears to play a vital role in determining the $\mathrm{CO}_{2}$ adsorption capacity and kinetics of aminemodified silica adsorbents due to the mass transfer limitations within extended meso-channel networks. Studies found that pore-expanded mesoporous silica supports with shorter mesochannels can outperform those with longer channels by a factor of 2.7 and 1.45 for PEI-impregnated MCM-41 and SBA15 in pure $\mathrm{CO}_{2}$ at $50{ }^{\circ} \mathrm{C}^{30}$ and a factor of 2.2 for amine-grafted SBA- 15 at $75{ }^{\circ} \mathrm{C}$ in $15 \% \mathrm{CO}_{2} / \mathrm{N}_{2},{ }^{35}$ respectively. However, despite the efforts in recent years, very few of the reported aminemodified conventional mesoporous silica materials have $\mathrm{CO}_{2}$ capture capacities greater than $3 \mathrm{mmol} \mathrm{g}^{-1}$ or $13.2 \mathrm{wt} \%$ in $15 \%$ $\mathrm{CO}_{2} / \mathrm{N}_{2}$ at the desirable adsorption temperature range of 50-75 ${ }^{\circ} \mathrm{C}$, due to amine loading limitations. Previous studies have demonstrated that for post-combustion capture, solid amine adsorbents with a $\mathrm{CO}_{2}$ capture capacity of $\mathrm{ca} .3 \mathrm{mmol} \mathrm{g}^{-1}$ for $50 \mathrm{wt} \%$ PEI loading are equivalent to $20 \mathrm{wt} \%$ aqueous MEA solvent when $90 \%$ of the $\mathrm{CO}_{2}$ in typical flue gas streams was captured. ${ }^{36,37}$ This suggests that more effective solid supports need to be explored to further improve the adsorption performance of immobilised amine adsorbents.

Clearly, a desirable solid support should best have large pore volume coupled with superior interconnectivity among the pores to maximise amine loading whilst reducing the mass transfer limitations of adsorption. Spherical mesocellular siliceous foam (MCF) represents a relatively new class of mesoporous silica materials with a continuous network comprised of uniform micro-spherical cells interconnected by large window pore channels, giving rise to a rigid macro-spherical geometry with a 3-dimensional porous framework with large pore size, pore volume and surface area. Compared with other mesoporous materials which usually consist of non-intersecting 
tubular pores, the unique geometrical configuration of MCF makes it a desirable category of support materials for preparing immobilised amine $\mathrm{CO}_{2}$ sorbents. Earlier investigations have demonstrated that mesocellular silica foam-supported PEI sorbents can significantly outperform other mesoporous silica materials by up to $30 \%$ for $\mathrm{CO}_{2}$ adsorption, with capacities reaching up to $3.5 \mathrm{mmol} \mathrm{CO}_{2}$ per $\mathrm{g}$ at $75{ }^{\circ} \mathrm{C}$ and 0.15 bar $\mathrm{CO}_{2},{ }^{38-40}$ compared to virtually all other mesoporous silicasupported PEIs with capacities being generally below $2.5 \mathrm{mmol}$ $\mathrm{CO}_{2}$ per $\mathrm{g}$ under similar conditions. ${ }^{28,35}$ To date, however, the impact of preparation and precursor chemistries on $\mathrm{CO}_{2}$ adsorption has not been examined adequately. In this study, a variety of siliceous cellular foam materials with varying cellular networks from meso-structured to macro-structured were prepared with different precursor and preparation chemistries, and their performance as the candidates for preparing high capacity $\mathrm{CO}_{2}$ adsorbents was evaluated.

\section{Experimental}

\subsection{Chemicals}

Non-ionic tri-block copolymer surfactant Pluronic P123 (EO20PO70-EO20, MWav = 5800), $\mathrm{HCl}(37 \%)$, 1,3,5-trimethylbenzene (TMB), tetraethyl orthosilicate (TEOS, 99.999\%), ammonium fluoride $\left(\mathrm{NH}_{4} \mathrm{~F}, 99.99 \%\right)$, and different branched polyethyleneimines with average molecular weights (MWs) varying from 600 to 60000 were all obtained from Sigma-Aldrich. PQ silica was obtained from PQ Corporation.

\subsection{Preparation of siliceous cellular foams and polyamine- impregnated $\mathrm{CO}_{2}$ adsorbents}

Porous siliceous cellular foams (SCFs) with variable pore and window sizes were synthesised using a modified version of the micro-emulsion method reported earlier by Schmidt-Winkel and co-workers, ${ }^{41}$ with the amphipathic surfactant P123 as the template and TMB as the pore-expanding agent. Briefly, in a typical preparation with TEOS as the silicon source and a TMB/P123 mass ratio of $1: 1,8 \mathrm{~g}$ of P123 was first dissolved in $150 \mathrm{ml}$ of $1.5 \mathrm{M} \mathrm{HCl}$ at $40{ }^{\circ} \mathrm{C}$ and then $8 \mathrm{~g}$ of TMB was added. Following $40 \mathrm{~min}$ of further stirring, $18.4 \mathrm{ml}$ of TEOS and $10 \mathrm{ml}$ of $2.5 \mathrm{M} \mathrm{NH}_{4} \mathrm{~F}$ solution (F/Si molar ratio 0.03 ) were added to the mixture under vigorous stirring and the resultant solution was kept at $40^{\circ} \mathrm{C}$ for variable times with continuous stirring. During this process, the hydrolysis of the TEOS at the surface of P123coated TMB droplets leads to the formation of a composite shell material with interconnected cells and windows at the areas of contact of adjacent droplets. The formed milky reaction mixture was then transferred into an autoclave and kept at 100 or $120^{\circ} \mathrm{C}$ for variable times under static conditions. The as-prepared white precipitate was separated by filtration and dried at ambient temperature. The dried precipitate was then calcined in air at $550{ }^{\circ} \mathrm{C}$ for 8 hours to obtain the porous silica support. The effect of preparation parameters on the surface textural properties of silica supports and hence the $\mathrm{CO}_{2}$ adsorptive properties of their supported polyamine sorbents was investigated, including the TMB/P123 ratio, aging time and aging temperature. For clarity and easy comparisons, the SCF materials synthesised under different conditions are denoted as SCF$x-y-z$ where $x, y$ and $z$ represent the TMB/P123 ratio, aging temperature and time, respectively. Table 1 summarises the preparation parameters examined.

Amine functionalisation of the SCF materials was achieved using a modified wet impregnation method. In this modified methodology, water rather than alkanols ${ }^{30,38,42}$ was used for the first time as the more cost-effective solvent. In a typical preparation, a calculated amount of selected polyamines was first dissolved in $10 \mathrm{ml}$ of water under continuous stirring for 20 min, and then the corresponding amount of SCF support was gradually added to the solution. After overnight stirring, the mixture was dried in a vacuum at $50{ }^{\circ} \mathrm{C}$ to yield PEI-functionalised SCF adsorbents. A branched PEI with an average molecular weight (MW) of 600, denoted as PEI-600, was used in most preparations but for selected SCF samples, other amines were also examined, including tetraethylenepentamine (TEPA) and other PEIs with variable MW from 1800 to 60000 . All the polyamines were obtained from Sigma-Aldrich. The PEI contents of the prepared SCF adsorbents were determined by TGA as the weight loss of the prepared SCF adsorbents when they were heated to $700{ }^{\circ} \mathrm{C}$ and burned in air $\left(100 \mathrm{~cm}^{3} \mathrm{~min}^{-1}\right)$ at the temperature to a constant weight. It was found that the weight losses obtained as the PEI contents agreed well with the pre-defined contents used in the impregnation, confirming the validity of the methodology.

\subsection{Characterisation of SCF materials}

The textural properties of the synthesised SCF materials were determined using nitrogen sorption isotherms with a Micromeritics ASAP 2420 apparatus at $77 \mathrm{~K}$. In a typical measurement, the silica was first degassed at $120{ }^{\circ} \mathrm{C}$ for 12 hours before analysis. Specific surface areas were determined using the Brunauer-Emmett-Teller (BET) equation. In addition, the pore

Table 1 Summary of preparation conditions for different SCF materials

\begin{tabular}{lllll}
\hline & $\begin{array}{l}\text { Initial P123 } \\
\text { concentration, } \\
\text { wt\% }\end{array}$ & $\begin{array}{l}\text { TMB/P123 } \\
\text { mass ratio }\end{array}$ & $\begin{array}{l}\text { Aging } \\
\text { temperature, }{ }^{\circ} \mathrm{C}\end{array}$ & $\begin{array}{l}\text { Aging } \\
\text { time, } \\
\text { hours }\end{array}$ \\
\hline SCF-0-100-24 & 5.0 & 0 & 100 & 24 \\
SCF-0.4-100-24 & 5.0 & 0.4 & 100 & 24 \\
SCF-0.7-100-24 & 5.0 & 0.6 & 100 & 24 \\
SCF-1-100-24 & 5.0 & 1 & 100 & 24 \\
SCF-1-70-24 & 5.0 & 1 & 70 & 24 \\
SCF-1-80-24 & 5.0 & 1 & 80 & 24 \\
SCF-1-90-24 & 5.0 & 1 & 90 & 24 \\
SCF-1-100-12 & 5.0 & 1 & 100 & 12 \\
SCF-1-100-42 & 5.0 & 1 & 100 & 42 \\
SCF-1-100-60 & 5.0 & 1 & 100 & 60 \\
SCF-1-120-42 & 5.0 & 1 & 120 & 42 \\
SCF-2-100-24 & 5.0 & 2 & 100 & 24 \\
SCF-2-100-42 & 5.0 & 2 & 100 & 42 \\
SCF-3-100-24 & 5.0 & 3 & 100 & 24 \\
SCF-3-100-42 & 5.0 & 3 & 100 & 42 \\
SCF-3-120-24 & 5.0 & 3 & 120 & 24
\end{tabular}


volume, pore size distribution, cell pore size and window size of the mesostructured silica were determined by using the BarrettJoyner-Halenda (BJH) method.

A JEOL 7100F Field Emission Gun Scanning Electron Microscope (FEG-SEM) (JEOL USA, Inc.) was used to illustrate the morphology and microstructure of the SCF samples while high resolution transmission electron microscopy (TEM) images were taken on a JEOL 2100F FEG-TEM at $200 \mathrm{kV}$.

\subsection{Characterisation of PEI-modified SCF adsorbents}

The $\mathrm{CO}_{2}$ adsorption-desorption performance of PEI-modified SCF adsorbents was evaluated with a TA500 thermogravimetric analyser (TA Instruments), using a simulated flue gas stream containing $15 \% \mathrm{CO}_{2}$ in $\mathrm{N}_{2}$. The amount of sample used in each TGA test was typically around 30 milligrams (mg) for different samples. Prior to any measurement, each individual sample was first subjected to pre-treatment at $120{ }^{\circ} \mathrm{C}$ in $\mathrm{N}_{2}$ for $20 \mathrm{~min}$ to remove any remaining moisture and/or pre-adsorbed gases, and the sample was then allowed to cool down to the selected temperature for adsorption tests. Three different types of $\mathrm{CO}_{2}$ adsorption measurements were performed, including (1) temperature-programmed $\mathrm{CO}_{2}$ adsorption, (2) $\mathrm{CO}_{2}$ adsorption isotherms at selected temperatures, and (3) the cycle lifetime performance testing of the sorbents.

For temperature-programmed adsorption, the sample was cooled down to $30{ }^{\circ} \mathrm{C}$ when the gas supply was switched from $\mathrm{N}_{2}$ to $15 \% \mathrm{CO}_{2}$ in $\mathrm{N}_{2}$. The sample was first held at this temperature for $30 \mathrm{~min}$ to reach equilibrium $\mathrm{CO}_{2}$ adsorption before the temperature was allowed to ramp to $130{ }^{\circ} \mathrm{C}$ at an extremely slow heating rate of $0.1{ }^{\circ} \mathrm{C} \mathrm{min}^{-1}$. The optimal adsorption temperature determined from the temperature-programmed adsorption test protocol was then selected to evaluate the $\mathrm{CO}_{2}$-capture performance of individual sorbent samples prepared. $\mathrm{CO}_{2}$ adsorption capacity was taken as the weight gain after the sample was exposed to the $\mathrm{CO}_{2}$-containing gas flows and reached equilibrium adsorption. The adsorption measurement was repeated typically three times for each sample or set of conditions and the average value was used.

Cyclic adsorption-desorption tests were also carried out. In each cyclic test, the sample was first allowed to reach equilibrium adsorption at $75{ }^{\circ} \mathrm{C}$ in the simulated flue gas and with the gas supply switched to $\mathrm{N}_{2}$, the sample was then heated up at a rate of $15{ }^{\circ} \mathrm{C} \mathrm{min}^{-1}$ to $130{ }^{\circ} \mathrm{C}$ and held at this temperature for $20 \mathrm{~min}$. The same procedure was repeated for 50 cycles. The gas

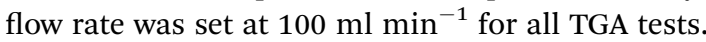

\section{Results and discussion}

\subsection{Surface textural and morphological characterisation of SCF materials}

Fig. 1 presents the nitrogen adsorption-desorption isotherms and pore size distributions of the porous SCF samples, which were synthesized under different conditions to reveal the effect of the precursor and preparation chemistries on the textural and morphological characteristics of the siliceous foams and hence their corresponding performance as candidate supports
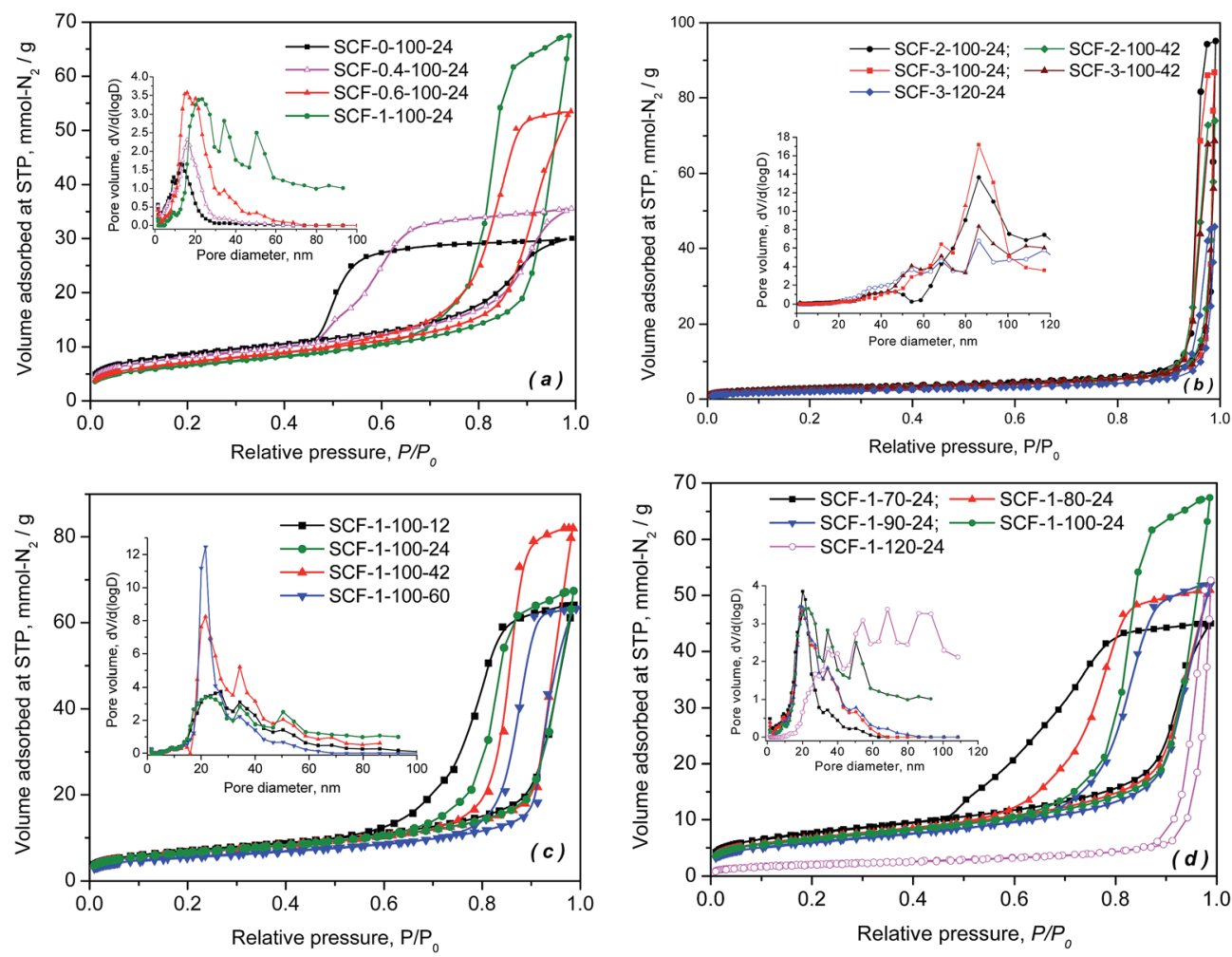

Fig. $1 \mathrm{~N}_{2}$ adsorption isotherms and pore size distributions of the SCF samples prepared with different precursor chemistries under different conditions. 
for preparing high capacity $\mathrm{CO}_{2}$ adsorbents. As shown in Fig. 1, all synthesised cellular forms were found to have type IV isotherms with steep but variable types of hysteresis in the high relative pressure region, which is characteristic of typical mesomodulated materials that exhibit ink-bottle or thermodynamic effects associated with the condensation and evaporation of the adsorbate in the adjoining mesopores with smaller connecting channels or bottle necks. With increasing TMB/P123 ratio as shown in Fig. 1(a) and (b), the sorption hysteresis loops shifted dramatically toward higher relative pressures with an increasing amount of $\mathrm{N}_{2}$ being adsorbed, which led to narrower pore size distributions (PSD) that also shifted toward larger pore diameters. This confirms the pore expansion behaviour of TMB. Meanwhile, with increasing amounts of TMB used, the pore hysteresis of the cellular materials also transformed from the wide H2 type hysteresis loops, which indicate the network nature of relatively uniform ink-bottle or channel-like pores, to the narrower $\mathrm{H} 1$ type hysteresis that is associated with the porous frameworks of higher pore size uniformity and facile pore connectivity. Clearly, the shift took place as a result of reduced curvatures or increased sizes of more uniform spherical composite micelles with increasing TMB concentration, due to the greater hydrophobic cores formed by the central hydrophobic polypropylene oxide chains of P123 dissolved into the non-polar TMB.

In general, the effect of aging time and temperature on pore hysteresis, as shown in Fig. 1(c) and (d), follows somehow the same trend as that of TMB. In general, the results demonstrate that an aging temperature of $100{ }^{\circ} \mathrm{C}$ and a $\mathrm{TMB} / \mathrm{P} 123$ ratio of 1.0 give better control over the pore size distributions particularly in the mesoporous region, while the cellular materials synthesised at $120{ }^{\circ} \mathrm{C}$ or with higher $\mathrm{TMB} / \mathrm{P} 123$ ratios $(\geq 2)$, such as SCF-1-120-24, SCF-3-120-42 and SCF-2-100-42, appear to be almost entirely macro-structured with reduced volumes of nitrogen adsorbed and wider pore size distributions centred between 60 and $90 \mathrm{~nm}$ (Fig. 1(b) and (d)).
Table 2 summarises the surface textural properties of the cellular foam samples derived from the sorption isotherms, while Fig. 2 presents the variation of pore volume, pore diameter and window size with the synthesis parameters. The cell diameter or the sizes of cell cavities of the cellular foams were calculated using the adsorption branches of the $\mathrm{N}_{2}$ isotherms, assuming that the pores are spherical, while the window size or the diameter of the channels connecting the pores was derived from the desorption branch of the isotherms (assuming cylindrical windows), using a modified BdB-FHH model proposed by Lukens et $a l .{ }^{43}$ It is evident that both the cell diameters and the window sizes increased significantly with increasing TMB concentration, aging time and aging temperature. Compared with the effect of aging time, however, the effect of TMB concentration and aging temperature appears to be more significant. At an aging temperature of $100^{\circ} \mathrm{C}$ and aging time of 24 hours, increasing the TMB/P123 ratio from 1 to 3 dramatically expanded the cell cavity size from 21.2 to $74.2 \mathrm{~nm}$ and the window size from $11.2 \mathrm{~nm}$ to $39.1 \mathrm{~nm}$, respectively, highlighting the novel pore expanding effects of TMB (Fig. 1(a)). Regarding the effect of aging temperature, although it appears to be quite modest at temperatures below $100{ }^{\circ} \mathrm{C}$, a sharp increase in both the pore diameters and window sizes was observed when the aging temperature was increased slightly from 100 to $120^{\circ} \mathrm{C}$, as shown in Fig. 1(b). Closer examinations of the results shown in Table 2 and Fig. 2 also interestingly reveal that compared to the window sizes, the cell diameters increased more significantly with increasing TMB concentration, aging time and aging temperature. This suggests that the condensation of silica, which was responsible for the formation of the shells of TMB-cored micelles or micro-emulsion droplets, was significantly enhanced due to the accelerated hydrolysis of TEOS and aggregation of smaller micelles at higher aging temperatures, TMB concentrations and longer aging times, leading to the formation of larger cells with denser and thicker shells or walls.

Table 2 Surface textural properties of the synthesised SCF materials

\begin{tabular}{|c|c|c|c|c|c|c|}
\hline Sample & $\begin{array}{l}\text { BET surface } \\
\text { area, } \mathrm{m}^{2} \mathrm{~g}^{-1}\end{array}$ & $V_{\text {total }}, \mathrm{cm}^{3} \mathrm{~g}^{-1}$ & $V_{\text {meso }}, \mathrm{cm}^{3} \mathrm{~g}^{-1}$ & $V_{\text {macro }}, \mathrm{cm}^{3} \mathrm{~g}^{-1}$ & Pore size, nm & $\begin{array}{l}\text { Window } \\
\text { diameter, nm }\end{array}$ \\
\hline SCF-0-100-24 & 715 & 1.1 & 0.9 & - & 8.1 & 4.4 \\
\hline SCF-0.4-100-24 & 668 & 1.3 & 1.1 & - & 10.4 & 5.1 \\
\hline SCF-0.6-100-24 & 591 & 1.8 & 1.7 & - & 15.9 & 10.9 \\
\hline SCF-1-100-24 & 547 & 2.2 & 2.1 & - & 21.2 & 11.2 \\
\hline SCF-1-70-24 & 631 & 1.5 & 1.4 & - & 13.8 & 6.1 \\
\hline SCF-1-80-24 & 561 & 1.7 & 1.6 & - & 16.4 & 7.9 \\
\hline SCF-1-90-24 & 493 & 1.8 & 1.7 & - & 16.7 & 10.8 \\
\hline SCF-1-100-12 & 571 & 2.1 & 2.0 & - & 19.3 & 8.6 \\
\hline SCF-1-100-42 & 549 & 2.8 & 2.7 & - & 25.4 & 13.4 \\
\hline SCF-1-100-60 & 451 & 2.2 & 2.1 & - & 24.3 & 15.1 \\
\hline SCF-1-120-42 & 168 & 1.8 & 0.72 & 0.91 & 52.8 & 34.3 \\
\hline SCF-2-100-24 & 240 & 2.8 & 0.31 & 2.77 & 57.9 & 39.7 \\
\hline SCF-2-100-42 & 217 & 2.5 & 0.56 & 1.91 & 61.3 & 38.7 \\
\hline SCF-3-100-24 & 198 & 3.2 & 0.27 & 2.5 & 74.2 & 39.1 \\
\hline SCF-3-100-42 & 223 & 2.4 & 0.38 & 1.99 & 62.2 & 39.4 \\
\hline SCF-3-120-24 & 165 & 1.6 & 0.23 & 1.37 & 50.9 & 44.4 \\
\hline PQ meso-porous silica & 269 & 1.7 & 1.7 & - & 24.7 & 18.6 \\
\hline
\end{tabular}



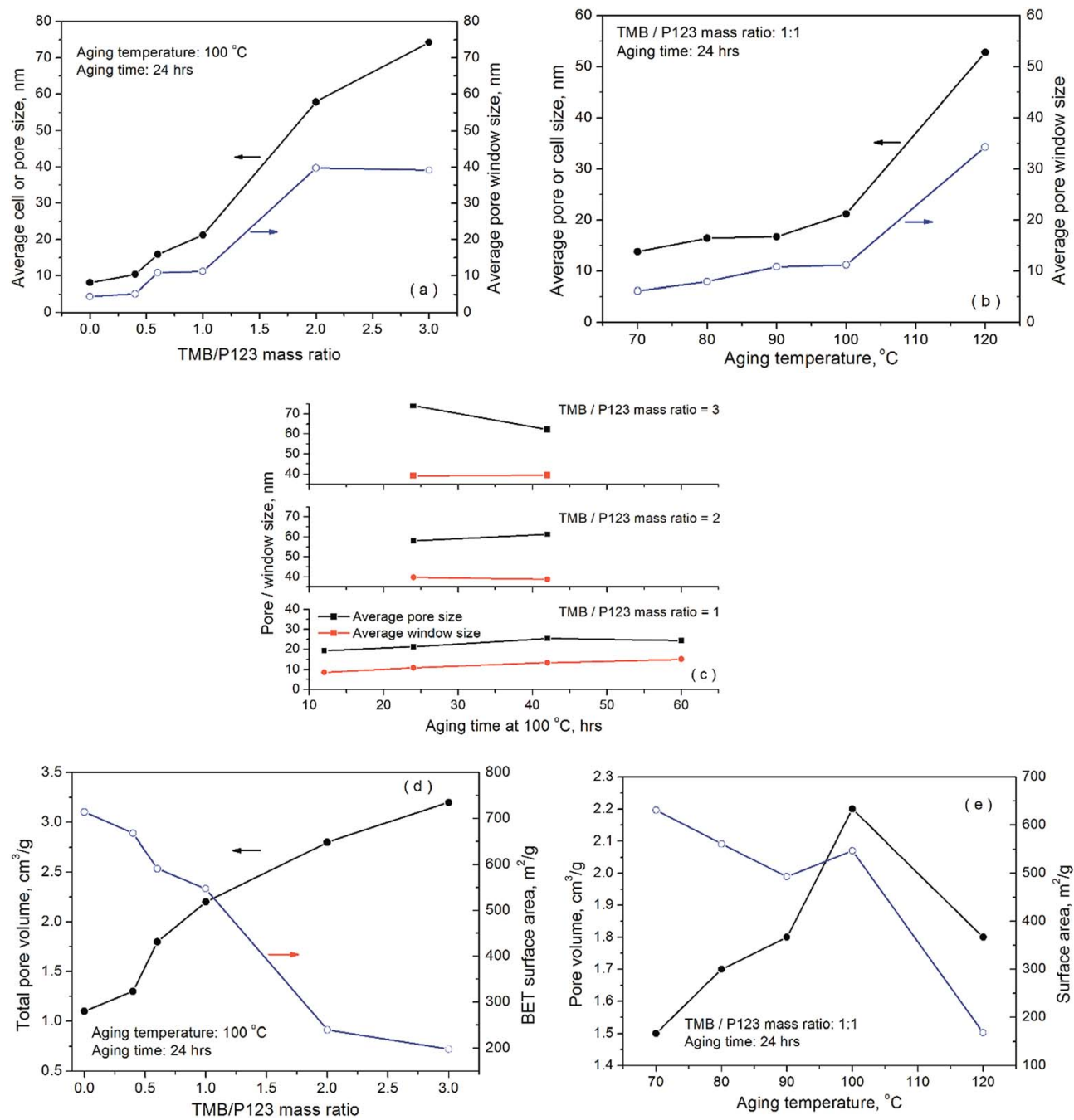

Fig. 2 Effect of precursor chemistry and preparation conditions on the surface textural properties of SCF material samples.

The surface area of the synthesised materials was found to depend heavily on the preparation conditions, varying from $714 \mathrm{~m}^{2} \mathrm{~g}^{-1}$ for the sample SCF-0-100-24 where no TMB was used to just $165 \mathrm{~m}^{2} \mathrm{~g}^{-1}$ for the sample SCF-3-120-24 prepared at $120^{\circ} \mathrm{C}$ and a TMB/P123 ratio of 2 . As expected, the surface areas were found to decrease significantly as the pore volumes increased with TMB concentration and aging temperature. This is, in principle, because the resultant enlarged windows cost disproportionately a larger fraction of the surface areas of the enlarged cells. Indeed, all the samples synthesised at $120^{\circ} \mathrm{C}$ and those at $100{ }^{\circ} \mathrm{C}$ but with high TMB/P123 ratios $(\geq 2)$ were found to have the lowest surface areas, generally well below $250 \mathrm{~m}^{2} \mathrm{~g}^{-1}$ but with largest pore diameters and window sizes (Table 2). In particular, the sample (SCF-3-120-24) prepared at an aging temperature of $120^{\circ} \mathrm{C}$ with a TMB/P123 ratio of 3 was found to have the largest window size of $44.4 \mathrm{~nm}$ but the lowest surface area of only $165 \mathrm{~m}^{2} \mathrm{~g}^{-1}$ and the smallest pore volume of $1.6 \mathrm{~cm}^{3} \mathrm{~g}^{-1}$. This further highlights the enhanced silica condensation as a result of accelerated hydrolysis of TEOS at high aging temperature and TMB concentrations, leading to increased cell diameters with reduced cell cavities and enlarged pore opening.
Schmidt-Winkel et al. ${ }^{41}$ found that the cell cavity or pore size has a linear relationship with the cubic root of the TMB/P123 mass ratio, which is in contrast to the direct linear relationship observed in a later investigation by Sridhar et al. ${ }^{44}$ However, no such linear relationships were obtained across the whole wider range of $\mathrm{TMB} / \mathrm{P} 123$ and aging temperatures examined in our investigation while our synthesised cellular foams were found to have significantly larger pore diameters and much lower surface areas compared to those obtained in previous investigations. ${ }^{41,44,45}$ Regarding the effect of precursor chemistry and preparation conditions on SCF wall thickness, van Grieken et al. and Schmidt-Winkel et al. both found that enhanced silica condensation is directly responsible for increased wall thickness, ${ }^{41,45}$ which contradicts the findings of Sridhar et al. ${ }^{44}$ that increased wall thickness is not a result of enhanced silica condensation but shrunken pore size and a transition of pore geometry from being spherical to cylindrical. However, the findings revealed in Fig. 2, Table 2 and the imaging analyses below (Fig. 3) indicate that a combination of enhanced silica condensation and pore geometry transition coupled with the aggregation of smaller TMB-cored micelles due to reduced 

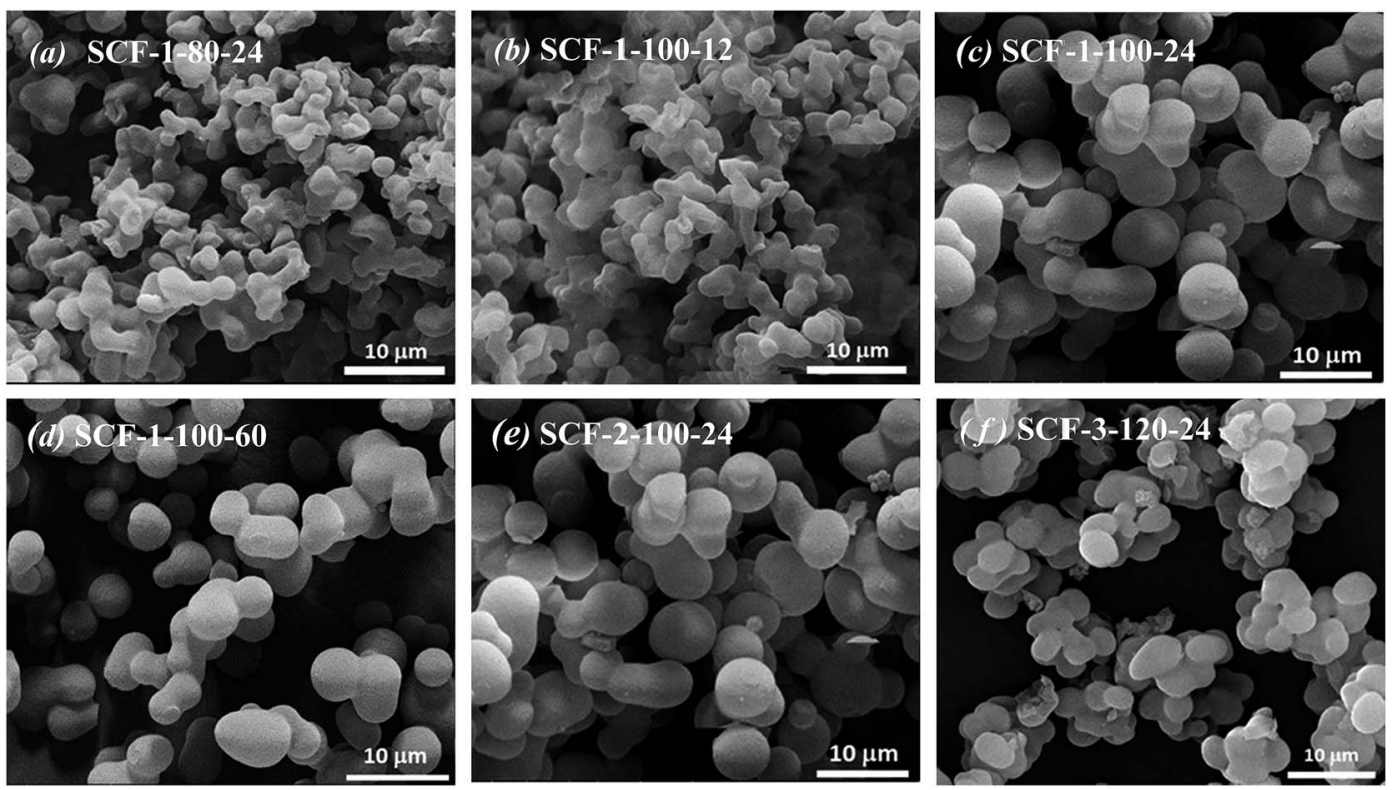

Fig. 3 FEG-SEM images of representative SCFs synthesized under different preparation conditions.

surface tensions is the most likely cause of the formation of larger cells with reduced cell cavities and enlarged window sizes at higher aging temperatures and TMB concentrations. The transition of pore hysteresis from $\mathrm{H} 2$ to $\mathrm{H} 1$ type as shown in Fig. 1 also corroborates the analyses above.

Fig. 3 and Fig. S1 $\uparrow$ show the morphological features at different microscopic scales of the typical cellular foams synthesised. As shown in Fig. 3(a) and (b), due to the extensive random aggregation observed among the smaller spheres of variable sizes, the siliceous particles prepared at lower aging temperatures and/or shorter aging times exhibit assembled coral-like cylindrical morphologies, which are somewhat similar to those of SBA- $15 .^{38}$ In contrast, the formation of significantly larger, more uniform and less packed spherical particles is evident when increasing the aging temperature from 80 to $100{ }^{\circ} \mathrm{C}$ (Fig. 3(a) and (c)) or the aging time from 12 to 60 hours (Fig. 3(b) and (d)). A further transformation from spherical to ellipsoidal particles that tend to assemble into larger spherical aggregates can be seen with further increase in aging temperature from 100 to $120^{\circ} \mathrm{C}$ and/or TMB/P123 ratio from 1 to 3. Closer examinations of the particle morphologies, as shown in Fig. $\mathrm{S} 1, \dagger$ reveal the open polygonal networks framed by silica struts, being characteristic of the structural features of siliceous cellular foams. ${ }^{41,46}$ Some deformations of the spherical cells are evident, probably caused by the unfavourable packing of the spherical micelles or the collapse of micellar cores during the packing due to their polydispersity. It can be seen that with increasing TMB concentration and aging temperature, the polygonal network structures became more developed and interconnected with increasingly more dense silica struts or thicker framework walls, while their sizes were found to be considerably less uniform with the formation of large empty voids or much greater cellular structures (Fig. S1(d)-(f) $\dagger$ ). The FEG-TEM images shown in Fig. S2 $\uparrow$ tend to suggest that the dense silica struts or walls of the SCF materials prepared at high aging temperatures with high $\mathrm{TMB} / \mathrm{P} 123$ ratios were composed of highly interconnected and open-celled nano-foamed structures, highlighting the significantly enhanced silica condensation at nano-porous scales. By and large, the morphological transformation is consistent with the variation of surface areas and pore size distributions with TMB concentration and aging temperature as shown in Table 2 and Fig. 2(d) and (e).

\section{2 $\mathrm{CO}_{2}$ adsorption-desorption of the amine-modified sorbents}

3.2.1 Quasi-static $\mathrm{CO}_{2}$ adsorption study. To examine the variation of $\mathrm{CO}_{2}$ uptake with temperature and hence to identify the optimal adsorption temperature, quasi-static $\mathrm{CO}_{2}$ adsorption tests were first conducted for PEI-modified SCF adsorbents at temperatures between ambient temperature and $120^{\circ} \mathrm{C}$ with a heating of $0.5^{\circ} \mathrm{C} \mathrm{min}^{-1}$. The use of such a low heating rate is to facilitate near equilibrium $\mathrm{CO}_{2}$ adsorption at individual adsorption temperatures in the range. Fig. 4 shows the results from the quasi-static tests for selected samples. As can be seen from Fig. 4, the $\mathrm{CO}_{2}$ uptake first increased and then decreased with adsorption temperature for all the samples examined, and the differences between the $\mathrm{CO}_{2}$ uptakes were significantly larger at lower adsorption temperatures. Meanwhile, the optimal adsorption temperature giving rise to the highest $\mathrm{CO}_{2}$ uptake also varied considerably for different samples, despite their same level of PEI loading at $60 \mathrm{wt} \%$. The sample SCF-3120-24 was found to have the lowest optimal adsorption temperature of $c a .71{ }^{\circ} \mathrm{C}$, compared to $75^{\circ} \mathrm{C}$ for SCF-1-100-24 and SCF-2-100-24 and the highest optimal of $80^{\circ} \mathrm{C}$ observed for the sample SCF-0-100-24, respectively.

Thermodynamically, low temperature favours the $\mathrm{CO}_{2}$ adsorption of amine-modified sorbent materials, but increasing adsorption temperature can help overcome the kinetic barrier 


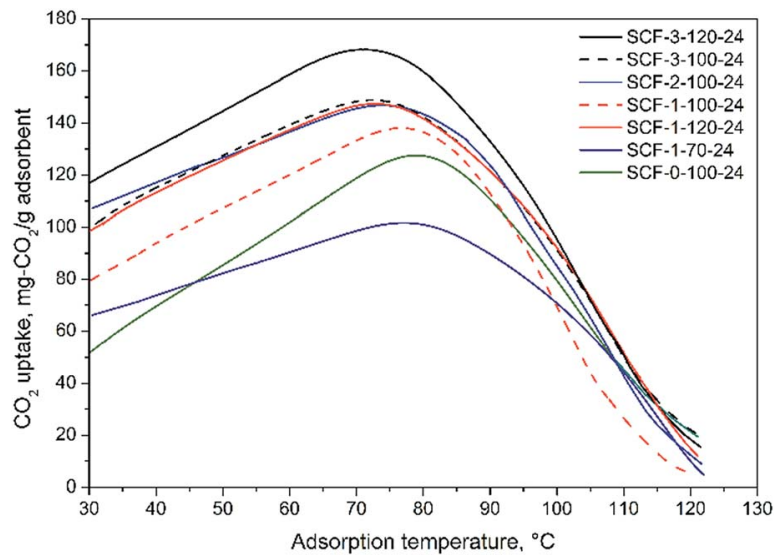

Fig. 4 Quasi-static $\mathrm{CO}_{2}$ adsorption tests of selected PEI (60\%)modified SCF adsorbents in simulated flue gas $\left(15 \% \mathrm{CO}_{2}\right.$ in $\left.\mathrm{N}_{2}\right)$. Conditions: heating rate of $0.5^{\circ} \mathrm{C} \mathrm{min}-1$ from ambient temperature to $120{ }^{\circ} \mathrm{C}$; content of PEI-600: $60 \mathrm{wt} \%$.

of $\mathrm{CO}_{2}$ adsorption due to the accordingly improved mobility and hence diffusivity and accessibility of the impregnated PEI molecules. ${ }^{27,42,47,48}$ The considerable differences observed in the optimal adsorption temperatures and $\mathrm{CO}_{2}$ uptakes reveal the different mass transfer limitations or diffusivities of $\mathrm{CO}_{2}$ in the amine sorbents. It is evident that irrespective of the pore volumes, the SCF materials synthesised at higher TMB concentrations or aging temperatures, which usually had larger pore diameters and wider window sizes, also have lower optimal adsorption temperatures in general. In addition, the results also show that although the differences between the variations of $\mathrm{CO}_{2}$ uptake with temperature diminished significantly at higher-than-optimal temperatures, the $\mathrm{CO}_{2}$ uptake of the samples with higher optimal adsorption temperatures generally decreased more rapidly with temperature, being indicative of the lower diffusional resistance of the desorbed $\mathrm{CO}_{2}$ when diffusing out through the pores and the bulk phase of immobilised amines during the desorption at higher temperatures. Presumably, for a given level of PEI loading, this is because larger pore and window sizes in an interconnected porous network can facilitate greater thermo-mobility and hence the kinetic behaviour of the immobilised amines through the pores such as to enhance the exposure of unreacted amine groups to $\mathrm{CO}_{2}$ or facilitate the $\mathrm{CO}_{2}$ diffusion deeper into the immobilised polymer amines, leading to higher amine efficiency or $\mathrm{CO}_{2}$ uptake of the sorbents. By and large, the results from the quasiequilibrium adsorption tests are generally in good agreement with the findings of Sakwa-Novak et al..$^{49}$ that improved amine mobility by adding additives can significantly increase the temperature sensitivity of immobilised amines for $\mathrm{CO}_{2}$ capture and hence the amine efficiency due to the resultant higher probability of intra-chain $\mathrm{CO}_{2}$ adsorption events. Builes and $\mathrm{Vega}^{27}$ also found that the high mobility of immobilised amines can facilitate the creation of a diffusive network of micro-cavities within the bulk phase of the amines, which favours the diffusion of $\mathrm{CO}_{2}$ in and out of the amines within the pores. Taking into account the surface textural properties (Table 2 and Fig. 2), the above results indicate that the formation of the diffusive network of micro-cavities can be better facilitated in the cellular materials with larger window sizes and somewhat greater pore diameters.

3.2.2 $\mathrm{CO}_{2}$ adsorption capacity of SCF-supported amine adsorbents. Fig. 5 shows the adsorption profiles of representative PEI-modified SCF adsorbents for each series of SCF materials synthesised. Despite the considerable variation of optimal adsorption temperatures for different SCFs, the $\mathrm{CO}_{2}$ adsorption capacities were all measured at the same temperature of $75{ }^{\circ} \mathrm{C}$ for the sake of consistent comparison. As can be seen from Fig. 5, all SCF samples showed significantly faster adsorption kinetics and higher $\mathrm{CO}_{2}$ capacities than the commercial benchmark silica (PQ Silicas), which is a highly meso-structured siliceous material with its pore volume, pore diameter and window size being similar to or even greater than those of the SCFs (Table 2). The times taken for the SCF adsorbents to achieve $80 \%$ and $90 \%$ of equilibrium $\mathrm{CO}_{2}$ capacity were found to be just $c a$. $1.5 \mathrm{~min}$ and $3 \mathrm{~min}$, which is nearly 8 times faster than the $c a .12$ and $23 \mathrm{~min}$ obtained for the PQ silica, respectively. This highlights the novel accessibility of the immobilised amines to $\mathrm{CO}_{2}$ due to the high levels of pore network connectivity in the SCF materials.

Table 3 compares the $\mathrm{CO}_{2}$ adsorption performance for all PEI-600-modified SCF materials at different PEI loading levels, while Fig. 6 shows the variation of $\mathrm{CO}_{2}$ uptake with the precursor chemistry and preparation conditions used. All PEImodified SCF adsorbents showed increased $\mathrm{CO}_{2}$ uptake capacities with increasing levels of PEI but with greater variations in $\mathrm{CO}_{2}$ capacity, determined by the preparation conditions. Among all the materials, SCF-3-120-24 gave rise to the highest $\mathrm{CO}_{2}$ adsorption capacity of $180.5 \mathrm{mg}$ per g-adsorbent at a PEI content of $70 \mathrm{wt} \%$, followed by SCF-2-100-42 (178.4 mg CO 2 per g) and SCF-3-100-42 (176.5 mg CO 2 per g), which are all significantly higher than those obtained previously for amine-modified mesoporous cellular foam materials $\mathrm{s}^{38-40}$ and virtually any other $2 \mathrm{D}$ mesoporous silica materials..$^{28,35,50-52}$ At $50 \mathrm{wt} \%$ and $60 \mathrm{wt} \%$ PEI, however, the highest $\mathrm{CO}_{2}$ uptake was instead obtained for SCF-1-100-60 at 150.4 and $168 \mathrm{mg} \mathrm{g}^{-1}$, respectively. It is noteworthy that with a total pore volume of just $1.1 \mathrm{~cm}^{3} \mathrm{~g}^{-1}$,

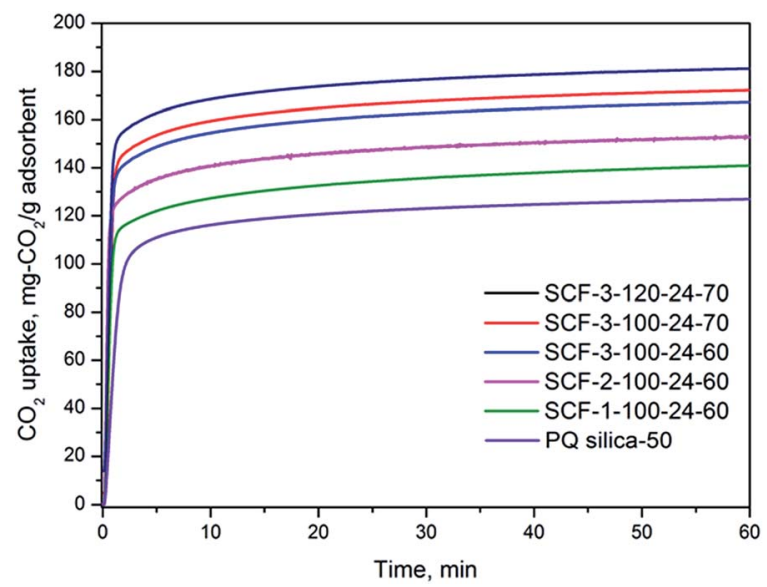

Fig. $5 \mathrm{CO}_{2}$ adsorption profiles of representative $\mathrm{PEI}$-impregnated SCF adsorbents in $15 \% \mathrm{CO}_{2} / \mathrm{N}_{2}$ at $75^{\circ} \mathrm{C}$. 
Table $3 \mathrm{CO}_{2}$ uptake capacities of PEI-impregnated SCF adsorbents with different PEI-600 contents at $75{ }^{\circ} \mathrm{C}$ in simulated flue gas $(15 \% \mathrm{CO} 2$ in $\mathrm{N}_{2}$ )

\begin{tabular}{|c|c|c|c|c|c|}
\hline \multirow{2}{*}{ Samples } & \multicolumn{5}{|c|}{$\mathrm{CO}_{2}$ uptake, $\mathrm{mg}-\mathrm{CO}_{2}$ per g-adsorbent } \\
\hline & $50 \mathrm{wt} \%$ & $60 \mathrm{wt} \%$ & $70 \mathrm{wt} \%$ & \multicolumn{2}{|l|}{ Max. $\mathrm{CO}_{2}$ uptake } \\
\hline SCF-0-100-24 & 118.2 & 139.4 & 107.1 & 139.4 & 232 \\
\hline SCF-0.4-100-24 & 125.2 & 143.2 & 140.2 & 143.2 & 239 \\
\hline SCF-1-70-24 & 85.3 & 103.5 & 67.8 & 103.5 & 173 \\
\hline SCF-1-80-24 & 91.6 & 128.4 & 119.5 & 128.4 & 214 \\
\hline SCF-1-90-24 & 100.6 & 138.4 & 154.7 & 154.7 & 221 \\
\hline SCF-1-100-12 & 113.3 & 139.2 & 151.0 & 151.0 & 215 \\
\hline SCF-1-100-42 & 137.3 & 151.3 & 173.9 & 173.9 & 248 \\
\hline SCF-1-100-60 & 150.4 & 172.1 & 144.4 & 172.4 & 287 \\
\hline SCF-3-100-42 & 112.4 & 149.8 & 176.5 & 176.5 & 252 \\
\hline SCF-3-120-24 & 116.7 & 156.4 & 180.8 & 180.8 & 258 \\
\hline PQ mesoporous silica & 127.4 & 113.8 & 104.7 & 131.4 & 255 \\
\hline
\end{tabular}
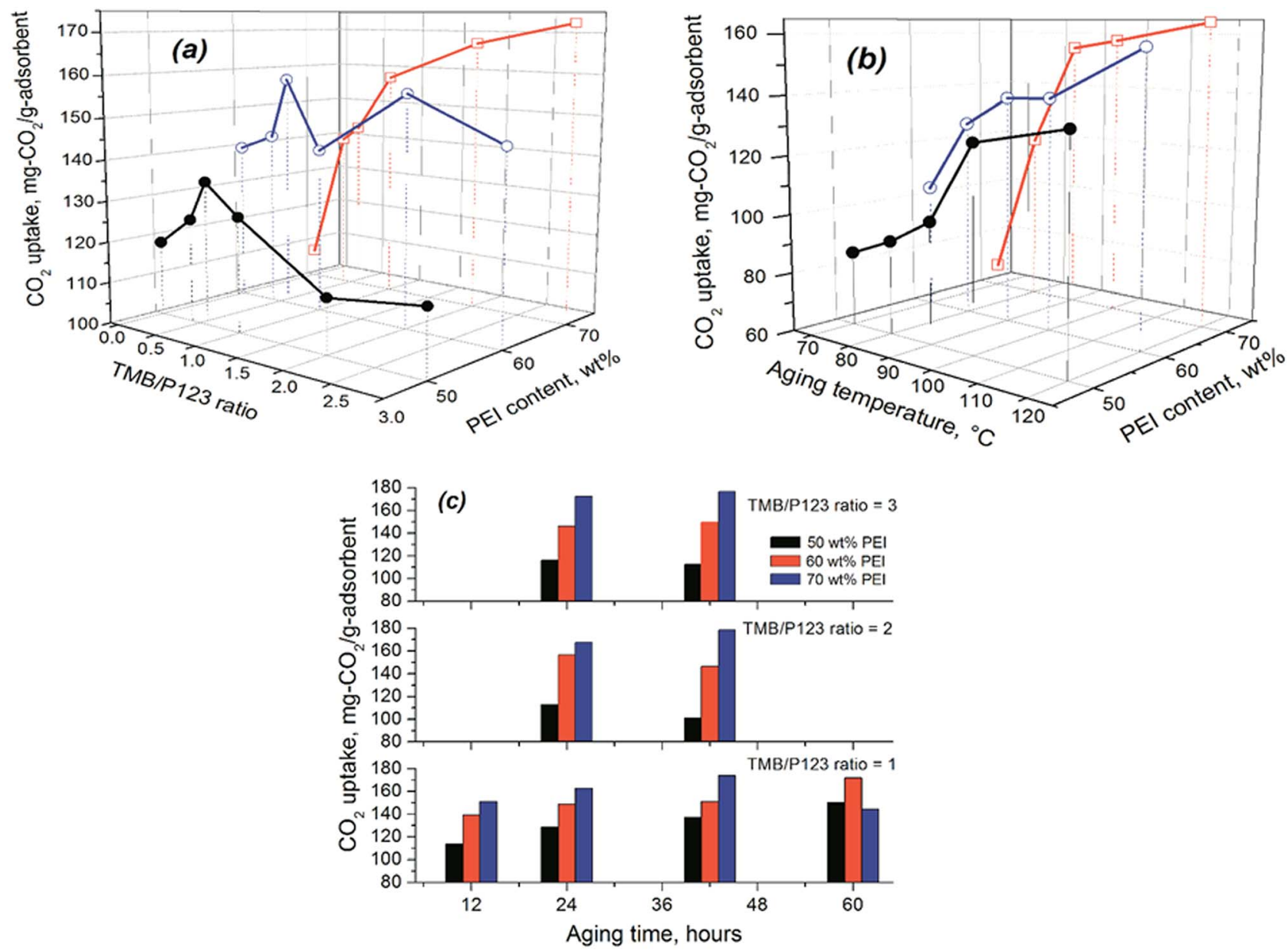

Fig. 6 Variation of the $\mathrm{CO}_{2}$ uptake of SCF materials with precursor chemistries and other preparation conditions. 
the SCF material prepared without the pore-expanding agent (SCF-0-100-24) also achieved a higher $\mathrm{CO}_{2}$ capacity of $138 \mathrm{mg}$ $\mathrm{CO}_{2}$ per g-ads than that of the baseline PQ silica material (127.4 $\mathrm{mg} \mathrm{CO}_{2}$ per g-ads) with an over $50 \%$ higher meso-pore volume $\left(1.7 \mathrm{~cm}^{3} \mathrm{~g}^{-1}\right)$, highlighting the importance of the 3D pore connectivity of the SCF materials. It appears that for the SCF materials prepared with lower TMB concentrations, there generally exists a maximum PEI loading level beyond which the $\mathrm{CO}_{2}$ adsorption capacity decreases with further increase in PEI loading, being consistent with previous findings on aminemodified MCFs. ${ }^{38,53}$ However, the same trend was not observed for those prepared with higher TMB concentrations or aging temperatures, which showed much lower $\mathrm{CO}_{2}$ uptake capacities but with a sharp continuous increase with increasing PEI loading up to $70 \mathrm{wt} \%$. Nevertheless, no further appreciable increases in $\mathrm{CO}_{2}$ uptake were obtained when levels of PEI impregnation were increased to higher than $70 \mathrm{wt} \%$ and the prepared sorbents started to become pasty.

Fig. 6 indicates that increasing TMB concentration and aging temperature/time led to increased $\mathrm{CO}_{2}$ adsorption capacity for all SCF materials, but the trend varied significantly for different individual conditions and PEI loading levels. As can be seen from Fig. 6(a), the effect of TMB concentration appears to depend on the amount of PEI immobilised in the SCF materials. At relatively lower PEI loading levels ( $\leq 60 \mathrm{wt} \%)$, the $\mathrm{CO}_{2}$ uptake first sharply increased with increasing the $\mathrm{TMB} / \mathrm{P} 123$ ratio from 0 to 1.0 and then decreased significantly when the ratio was further increased from 1 to 3 . This instead led to lower $\mathrm{CO}_{2}$ capacities or amine efficiencies for the bestperforming SCF materials that were synthesised all with high $\mathrm{TMB} / \mathrm{P} 123$ ratios $(\geq 2)$, compared to those prepared with lower TMB concentrations, as shown in Fig. 6(a). However, at a higher PEI loading level of $70 \mathrm{wt} \%$, no such trend was observed as can be seen from the continuous increase of the $\mathrm{CO}_{2}$ uptake with TMB concentration. This is clearly because of the variable maximum PEI-accommodating abilities, which were lower for the SCF materials synthesised with lower TMB concentrations and aging temperatures (Table 3). A similar trend was also observed on the effect of aging time, namely an increase in aging time led to reduced $\mathrm{CO}_{2}$ capacity or amine efficiency at lower PEI contents for the SCF substrates synthesised using high TMB/P123 ratios. In comparison, all SCF materials showed a continuous increase in $\mathrm{CO}_{2}$ uptake with aging temperatures at all PEI loading levels, as indicated in Fig. 6(b). It is noteworthy that despite the variable trends observed, the SCF materials prepared with higher TMB/P123 ratios $(\geq 2)$ and aging temperatures $\left(>100{ }^{\circ} \mathrm{C}\right)$ all exhibited greater $\mathrm{CO}_{2}$ adsorption capacities.

In theory, given the similar nature of the SCF materials all with interconnected $3 \mathrm{D}$ porous structures, the $\mathrm{CO}_{2}$ capacity of the range of SCF-based adsorbents should be proportional to the amount of PEI impregnated onto the SCF substrates, which is in turn determined by the total pore volume of the substrates. Previous investigations have found that the total pore volume was the decisive factor affecting the $\mathrm{CO}_{2}$ uptake at high amine loading levels particularly for meso-structured support materials with $2 \mathrm{D}$ hexagonal symmetries..$^{38,42,54,55}$ Fig. 7 shows the
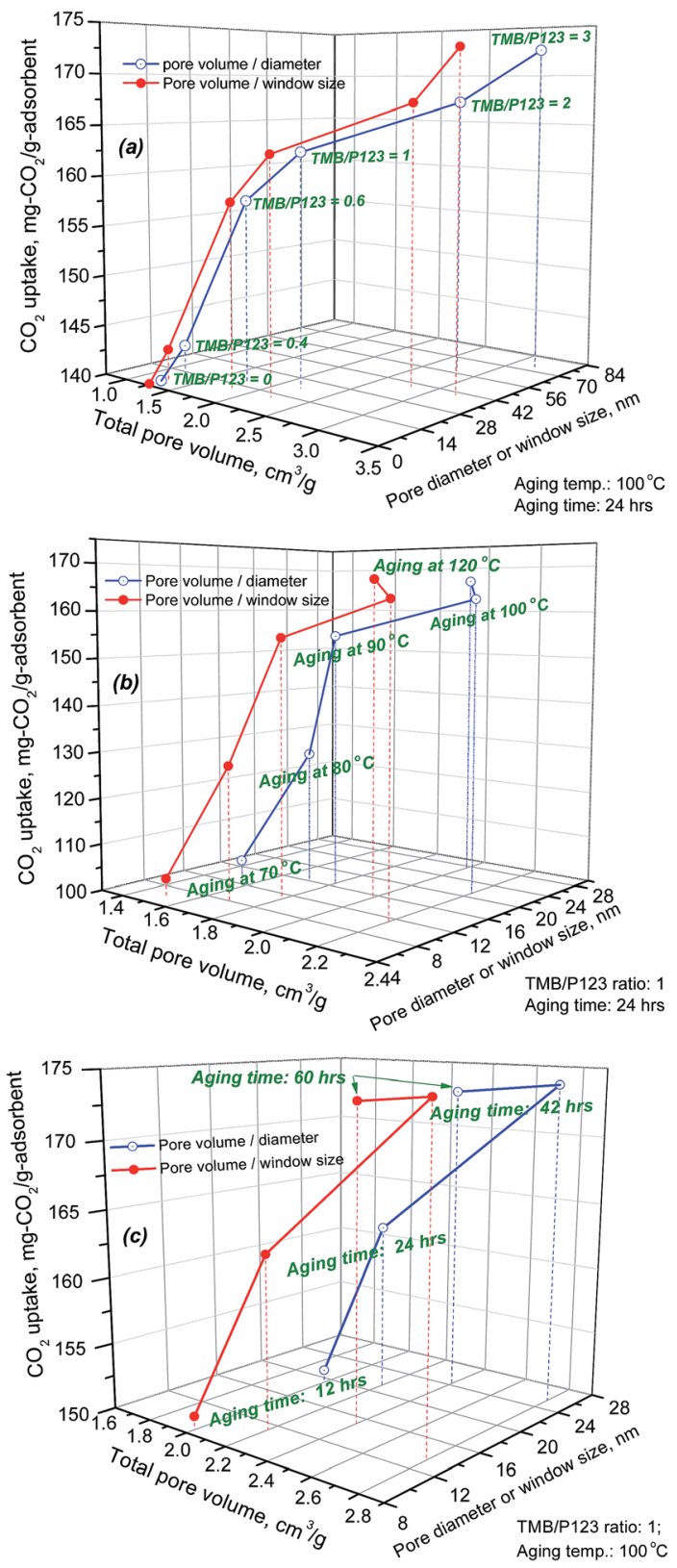

Fig. 7 Effect of total pore volume, pore diameter and pore window size on the maximum $\mathrm{CO}_{2}$ uptake capacity of the SCF materials synthesised under different conditions.

variation of $\mathrm{CO}_{2}$ uptake capacity as a function of the surface textural properties of the SCF materials. It is evident that the $\mathrm{CO}_{2}$ uptake capacity increased dramatically with the total pore volume, pore diameter and window size of the SCF substrates, particularly for the SCF materials synthesised at lower TMB concentrations and/or aging temperatures. In addition, closeto-linear relationships can also be observed between the $\mathrm{CO}_{2}$ uptake and the total pore volume for the SCF substrates with pore volumes lower than $2.2 \mathrm{~cm}^{3} \mathrm{~g}^{-1}$ and pore diameters/ window sizes below $28 \mathrm{~nm}$ as shown in Fig. 7(a) and (c). For the SCFs with larger pore volumes or pore diameter/window sizes, the $\mathrm{CO}_{2}$ uptake deviated from the linear relationship toward lower $\mathrm{CO}_{2}$ uptakes, indicating the lower amine efficiencies or 
that the pores could not possibly be fully impregnated with PEI to give higher $\mathrm{CO}_{2}$ capacity.

However, it needs to be emphasised that all the best-performing SCF materials, which were the macro-structured siliceous foam materials synthesised with high TMB/P123 ratios $(\geq 2)$ and aging temperatures $\left(120^{\circ} \mathrm{C}\right)$ or long aging times $(>24$ hours), all interestingly exhibited the lowest $\mathrm{CO}_{2}$ capacities or amine efficiencies at low PEI impregnation levels but their $\mathrm{CO}_{2}$ uptake capacities were found to increase much more sharply with PEI impregnation, instead giving rise to the highest $\mathrm{CO}_{2}$ capacities at high PEI loading levels among all the materials as shown in Table 3 and Fig. 6(a and b). These anomalies were found to be largely responsible for the significant data scattering observed in the above correlations (Fig. 7) where SCF-2100-42, SCF-3-100-42 and SCF-3-120-42 were excluded. For instance, SCF-3-120-24, which had the lowest total pore volume of only $1.6 \mathrm{~cm}^{3} \mathrm{~g}^{-1}$ and surface area of $165 \mathrm{~m}^{2} \mathrm{~g}^{-1}$, had one of the lowest $\mathrm{CO}_{2}$ uptakes at $117 \mathrm{mg}-\mathrm{CO}_{2}$ per g-ads $(233 \mathrm{mg}$ per gPEI) at $50 \mathrm{wt} \%$ PEI but it achieved the highest $\mathrm{CO}_{2}$ uptake of $180.8 \mathrm{mg}-\mathrm{CO}_{2}$ per g-adsorbent ( $258 \mathrm{mg}-\mathrm{CO}_{2}$ per g-PEI) with 70 wt\% PEI loading among all the SCF materials, and this compares to that of the SCF-1-100-24 sample, which has a higher capacity of $128.7 \mathrm{mg}-\mathrm{CO}_{2}$ per g-ads $\left(257.4 \mathrm{mg}-\mathrm{CO}_{2}\right.$ per $\mathrm{g}$-PEI) at $50 \mathrm{wt} \%$ PEI but has a much lower capacity of just 162.7 $\mathrm{mg}-\mathrm{CO}_{2}$ per g-ads $\left(232 \mathrm{mg}\right.$ - $\mathrm{CO}_{2}$ per g-PEI) at $70 \mathrm{wt} \%$ PEI. Meanwhile, SCF-3-100-24, which had the largest pore volume of $3.2 \mathrm{~cm}^{3} \mathrm{~g}^{-1}$, gave rise to a $\mathrm{CO}_{2}$ uptake of just $172.5 \mathrm{mg} \mathrm{CO}_{2}$ per gads, which was considerably lower than those of SCF-3-120-24 and other materials with much lower pore volumes. Similar comparisons can also be drawn between SCF-3-100-42 and SCF1-100-42, SCF-2-100-42 and SCF-1-100-60 and SCF-3-120-24 and SCF-1-100-24.

The findings that macro-structured siliceous foams outperform their meso-structured counterparts in $\mathrm{CO}_{2}$ uptake have not been observed in previous investigations, which mostly focused on meso-structured $\mathrm{MCFs}^{38-40}$ and other silica materials. ${ }^{28,35,50-52,55}$ In addition, Yan et $a l .^{38}$ found that the pore window size, when larger than $8.6 \mathrm{~nm}$, is no longer an important factor affecting the impregnation and distribution of PEIs and hence the $\mathrm{CO}_{2}$ capacity of PEI-modified MCFs. This clearly cannot be generalised to the SCFs in this investigation probably because of the small number of samples or conditions examined previously. ${ }^{29,38-40,52,53}$

Clearly, the exceedingly high $\mathrm{CO}_{2}$ uptake performance of the highly macroporous SCF materials cannot be accounted for solely by their greater porosities and pore geometries. Closer examinations of the surface textural results shown in Table 2, Fig. 2, 3 and $\mathrm{S} 1 \dagger$ reveal that the SCF materials prepared at higher aging temperatures, longer aging times and higher TMB concentrations all expectedly had increased pore diameters and/or window sizes but with drastically reduced surface areas (Table 2). In addition, it seems that the effect of aging temperature and time on the surface textural properties of the SCF materials depends on the TMB concentrations used in the synthesis. Further, as shown in Table 2 and Fig. 2, the effect of aging temperature and time on the surface textural properties at high TMB concentrations was also found to differ from the effect at low TMB concentrations in that at high TMB concentrations, further increase in aging time from 100 to $120{ }^{\circ} \mathrm{C}$ or aging times from 24 to 42 hours led to significantly reduced, rather than increased, pore volumes and macro-pore sizes (e.g. SCF-3-120-24 vs. SCF-3-100-24 and SCF-3-100-42 vs. SCF-3-10024) with boosted silica struts or cell wall thickness as shown in Fig. S1(e) and (f). $\dagger$ This essentially led to the formation of mixed meso/macro-cellular SCFs with relatively wider but regular pore size distributions as shown in Fig. 1(b) and (d). It is therefore believed that the formation of the ordered meso/macro-porous SCF materials with enhanced silica strut structures, which serve as the framework platforms for impregnation, can facilitate higher PEI impregnation levels and more importantly, greater mobility or diffusivity of the immobilised bulk amines, which is vital in boosting the accessibility to $\mathrm{CO}_{2}$ molecules. This hypothesis is strongly supported not only by the high amine efficiencies achieved by the SCFs at high PEI impregnation levels but also their lower optimal adsorption temperatures, which act as an indicator of the amine mobility, and the faster adsorption kinetics at high PEI loading levels, which indicates the low $\mathrm{CO}_{2}$ diffusion resistance within the bulk phase of the supported PEI amines, as shown in Fig. 4. However, the significantly lower surface areas of the highly meso/macrocellular SCFs, which decreased from typically over $500 \mathrm{~m}^{2}$ per $\mathrm{g}$ ads to below $250 \mathrm{~m}^{2}$ per g-ads, may lead to lower $\mathrm{CO}_{2}$ uptake capacities at low PEI loading levels due to the disproportionately reduced larger number of available top surface amine sites due to the accordingly increased coating thickness, which cannot be offset by the increased amine mobility of the bulk impregnated PEI at low loading levels.

3.2.3 $\mathrm{CO}_{2}$ adsorption capacity of SCF materials modified with varying molecule weight PEIs. Binary impregnation was examined as a means to further improve the $\mathrm{CO}_{2}$ adsorption performance of the amine-modified SCF adsorbents. The results above suggest that the accessibility of the bulk phase of impregnated PEIs plays a vital role in determining the $\mathrm{CO}_{2}$ uptake capacity of the PEI-SCF adsorbents, which is affected heavily by both the surface textural and morphological properties of the SCF materials that govern the distribution state of the impregnated PEIs. Previous investigations have confirmed that the use of surfactants in amine impregnation can facilitate additional $\mathrm{CO}_{2}$ pathways within the bulk phase of immobilised amines and hence improve the mobility and accessibility of the amines for higher amine efficiencies and $\mathrm{CO}_{2}$ capture capacities, and $\mathrm{CO}_{2}$-unreactive surfactants were typically used, such as sodium dodecylsulfate, ${ }^{56} \mathrm{P} 123$, STAB and SPAN $80^{57}$ and CTAB and polyethylene glycol of different molecular weights. ${ }^{49}$ Instead of using $\mathrm{CO}_{2}$-unreactive surfactants, tetraethylenepentamine (TEPA), which is a type of low molecular weight PEI, was used as the substitute for surfactants to prepare the binary PEI adsorbents via co-impregnation, and two best performing SCF support materials, namely SCF-3-120-24 and SCF-3-100-24 were selected for the preparations. Fig. 8 presents the $\mathrm{CO}_{2}$ uptake performance of the binary SCF adsorbents.

As can be seen from Fig. 8, the binary amine-modified SCF adsorbents achieved significantly higher $\mathrm{CO}_{2}$ uptake for both 

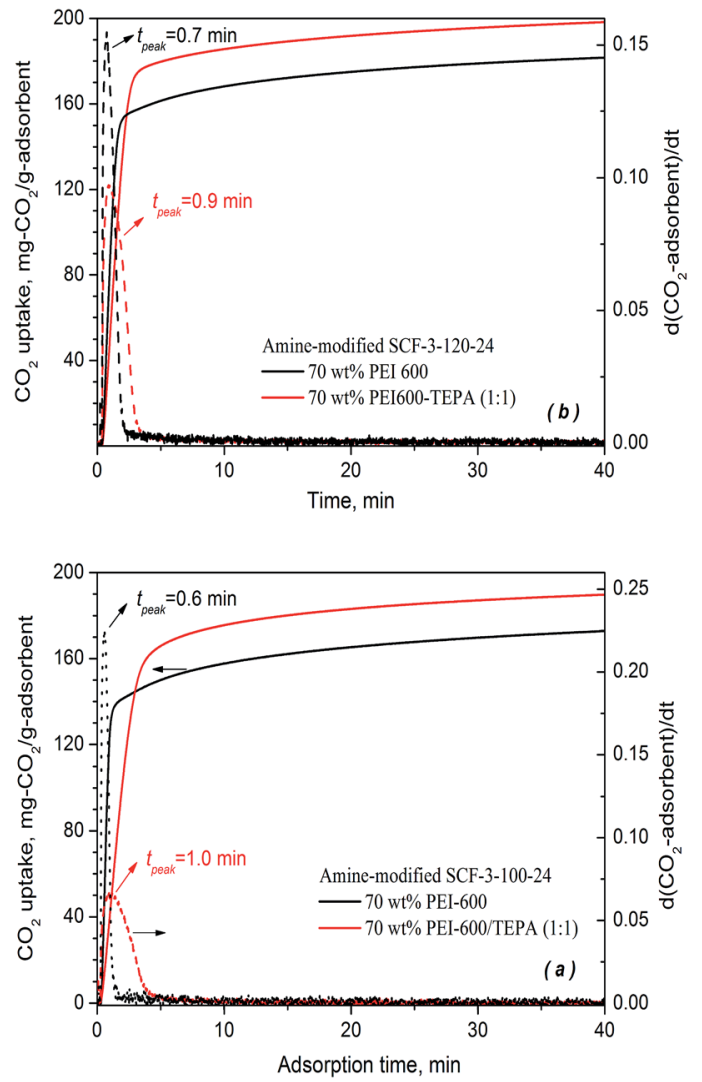

Fig. $8 \mathrm{CO}_{2}$ adsorption profiles of binary amine-modified SCF adsorbents at $75^{\circ} \mathrm{C}$ in a simulated flue gas of $15 \% \mathrm{CO}_{2}$ in $\mathrm{N}_{2}$.

SCF materials examined at an amine loading level of $70 \mathrm{wt} \%$. The TEPA-PEI modified SCF-3-120-24 reached an exceedingly high $\mathrm{CO}_{2}$ capacity of $198.2 \mathrm{mg}-\mathrm{CO}_{2}$ per g-ads, $10 \%$ higher than its PEI-modified counterpart ( $180.8 \mathrm{mg}-\mathrm{CO}_{2}$ per g-ads). A similar increase in $\mathrm{CO}_{2}$ uptake by approximately $10 \%$ was also obtained for SCF-3-100-24, from $172.5 \mathrm{mg}-\mathrm{CO}_{2}$ per g-ads for PEI impregnation to $190 \mathrm{mg}-\mathrm{CO}_{2}$ per g-ads for PEI-TEPA coimpregnation. The $\mathrm{CO}_{2}$ capacities obtained for the binary SCF adsorbents represent the highest ever reported under similar conditions. ${ }^{58-60}$

Nevertheless, it appears that at the early stage of adsorption, the binary co-impregnation resulted in somewhat slower adsorption kinetics, as opposed to the faster kinetics expected for the lower viscosity and more reactive amine groups of TEPA compared to the higher molecular weight PEI-600. For SCF-3100-24, the time taken to achieve $80 \%$ of equilibrium capacity increased from $1.4 \mathrm{~min}$ for PEI impregnation to $3.2 \mathrm{~min}$ for the PEI/TEPA co-impregnation whereas for the SCF-3-120-24 material, the time increased from 1.6 to $2.4 \mathrm{~min}$, respectively. Meanwhile, the peak adsorption time $\left(t_{\max }\right)$ increased from 0.6 to $1.0 \mathrm{~min}$ for SCF-3-100-24 and slightly from 0.7 to $0.9 \mathrm{~min}$ for SCF-3-120-24, respectively, when the impregnation changed from PEI-600 to the mixture of TEPA and PEI-600. The results differ from the previous findings that the use of blended amines, such as TEPA and DEA, for impregnation resulted in faster rates of adsorption kinetics in addition to higher capacities. Presumably, the lower rate of adsorption kinetics of the binary SCF adsorbents is because of the potentially more dense bulk phase packing of the binary amines as the much less viscous and smaller TEPA molecules can penetrate into the micro-cavities created by the larger PEI-600 molecules, leading to steric crowding within the bulk phase of the impregnated mixed amines and hence increased diffusion resistance for $\mathrm{CO}_{2}$ migration. ${ }^{27}$ This kind of effect may not be significant in the case of the co-impregnation of TEPA and DEA, because of their similar molecular sizes and when the adsorption takes place at low temperatures..$^{58,59}$

In addition to the co-impregnation of amines of different molecular weights, attempts were also made to examine the suitability of the synthesised SCF materials for impregnating higher molecular mass PEIs as a measure to improve the thermal stability of the adsorbents. The development of amineimpregnated adsorbents for $\mathrm{CO}_{2}$ capture has so far been mostly limited to the use of low molecular weight amines, such as TEPA, DEA and PEIs with a molecular mass typically below 1800 , because they are less viscous and can facilitate faster adsorption kinetics and higher adsorption capacity at the same impregnation levels. However, the supported lower molecular mass amines usually have lower thermal stability, giving rise to inevitable amine loss due to evaporation and thermal decomposition loss in long term operations. ${ }^{61}$ To this end, higher molecular mass PEIs do offer some considerable advantages. However, in terms of adsorption capacity and kinetics, the $\mathrm{CO}_{2}$ adsorption performance of higher molecular mass PEIs can be sluggish due to their higher viscosities and tertiary amine contents, ${ }^{62}$ and thus more robust porous support materials are required to mitigate the negative impact. To further investigate the ability of the synthesised SCF materials to accommodate higher molecular weight PEIs as a means to improve the thermal stability of supported PEI sorbents, the meso-structured SCF-1-100-24 was selected as the support for the impregnation of higher molecular mass PEIs. Fig. 9 shows the $\mathrm{CO}_{2}$ adsorption performance in comparison with the baseline 2D meso-structured PQ silica material.

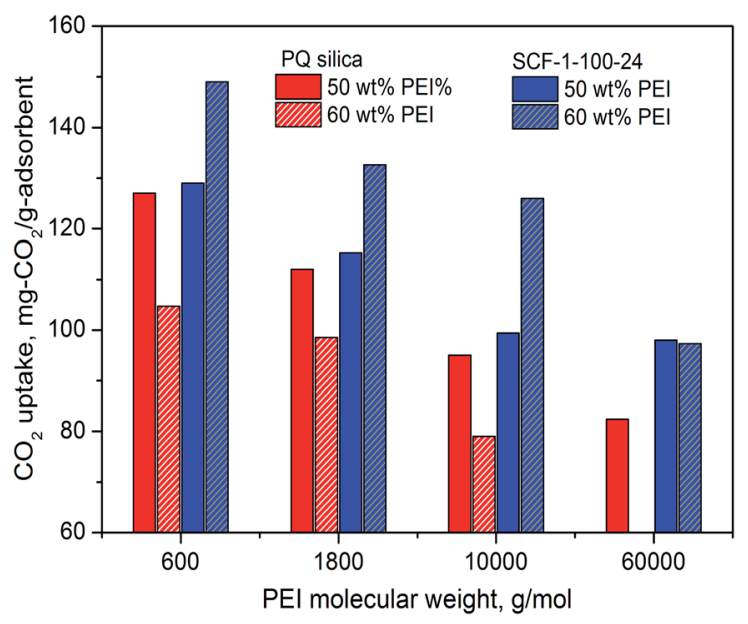

Fig. 9 Comparison of the $\mathrm{CO}_{2}$ adsorption performance of the SCF materials modified with different molecular mass PEls measured at 75 ${ }^{\circ} \mathrm{C}$ in simulated flue gas $\left(15 \% \mathrm{CO}_{2}\right.$ in $\left.\mathrm{N}_{2}\right)$. 
As expected, the results demonstrate that the $\mathrm{CO}_{2}$ capacity decreased considerably for both the SCF and the baseline 2D meso-porous PQ silica with the increase of PEI molecular weight. At $50 \%$ PEI content, the $\mathrm{CO}_{2}$ adsorption capacity of the PQ silica supported PEI dropped from 127.4 to $95 \mathrm{mg}$ mg- $\mathrm{CO}_{2}$ per g-ads as the molecular mass of PEI increased from 600 to 60 000, whereas the capacity of SCF-1-100-24 with 60 wt\% PEI loading decreased from $148.9 \mathrm{mg}-\mathrm{CO}_{2}$ per g-ads to $127 \mathrm{mg}-\mathrm{CO}_{2}$ per g-ads, respectively. It is important to highlight that the meso-structured siliceous cellular foams facilitated significantly higher $\mathrm{CO}_{2}$ capacities than the benchmark PQ silica for all the higher molecular mass PEIs at all impregnation levels examined, with their $\mathrm{CO}_{2}$ capacity increasing significantly with increasing levels of impregnation. At $60 \mathrm{wt} \%$ PEI content, the PEI-modified SCF adsorbent gave rise to impressive capacities of 126 and $97.3 \mathrm{mg}$-CO $\mathrm{CO}_{2}$ per g-ads for PEI-10 000 and PEI-60 000, respectively, which are even significantly higher than those reported for PEI-1800 modified PQ silica ${ }^{63}$ and PEI-2500 modifiedMCF. ${ }^{40}$ In contrast, the $\mathrm{CO}_{2}$ adsorption capacity of the PEIimpregnated mesoporous PQ silica decreased sharply with increasing levels of the PEIs and no appreciable capacities could be measured at an impregnation level of $60 \mathrm{wt} \%$ for PEI-60 000. This highlights that the SCF materials are particularly suitable for preparing high molecular mass PEI adsorbents via impregnation with significantly improved thermo-stability only at a modest cost of $\mathrm{CO}_{2}$ capacities.

3.2.4 Cyclic adsorption-desorption performance testing of PEI-modified SCF materials. The regenerability or cyclic adsorption-desorption performance of a $\mathrm{CO}_{2}$ adsorbent is critical in determining their life-time importance in practical applications. Therefore, some of the best-performing PEI-600modified SCF adsorbents are selected for cyclic performance testing under simulated flue gas conditions. As shown in Fig. 10, no appreciable changes in $\mathrm{CO}_{2}$ uptake were observed from the 50 cycles of adsorption-desorption tests for different selected samples, highlighting the novel thermo-stability and

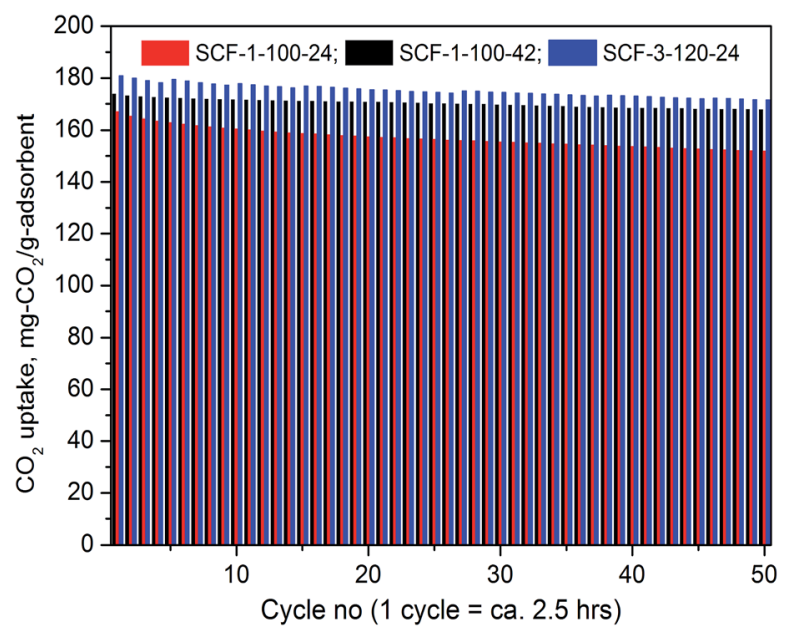

Fig. 10 Cyclic adsorption-desorption profiles of PEI-600-modified SCF materials for $\mathrm{CO}_{2}$ uptake under simulated flue gas conditions $(15 \%$ $\mathrm{CO}_{2}$ in $\mathrm{N}_{2}$ ). Conditions: adsorption temperature: $75^{\circ} \mathrm{C}$; desorption temperature: $130{ }^{\circ} \mathrm{C}$; heating rate: $15^{\circ} \mathrm{C} \mathrm{min}{ }^{-1}$. fully reversible $\mathrm{CO}_{2}$ adsorption of the adsorbents. The negligible losses observed in the first few cycles were believed to be mainly associated with the evaporation loss of small quantities of lower molecular mass PEI components present in the PEI. In addition, it seems that the SCF materials prepared at higher aging temperatures or longer aging times present considerably higher thermal stability, which is attributable to the presumably increased holding strength of the materials for the impregnated PEI due to their denser and thicker shells as shown in Fig. 3 and $\mathrm{S} 1 . \dagger$

\section{Conclusions}

A wide range of meso, hybrid meso/macro and macro-structured siliceous cellular foam (SCF) materials have been tailordesigned and fabricated for preparing PEI-modified highly efficient adsorbent materials for $\mathrm{CO}_{2}$ capture. The results demonstrate that while all the SCF materials exhibited higher capacities and faster adsorption kinetics in comparison with conventional meso-structured materials with 2D hexagonal pore geometries, all best-performing SCF materials are the hybrid meso/macro and macro-structured materials prepared using high TMB concentrations, high aging temperatures and longer aging times despite their drastically reduced surface areas. The $\mathrm{CO}_{2}$ uptake capacity of the SCF materials reached up to $180.2 \mathrm{mg}-\mathrm{CO}_{2}$ per g-adsorbent (5.85 mmol per g-amine) for PEI impregnation and was further improved to $198.2 \mathrm{mg}-\mathrm{CO}_{2}$ per g-adsorbent $(6.44 \mathrm{mmol}$ per g-amine) for the binary impregnation of PEI-TEPA at $75{ }^{\circ} \mathrm{C}$ in a simulated flue gas of $15 \% \mathrm{CO}_{2}$ in $\mathrm{N}_{2}$, which are significantly higher than the previously reported under similar or comparable conditions. The macro- and hybrid meso/macro-structured SCF materials were also found to be particularly suitable for preparing high molecular weight PEI-modified adsorbents with significantly improved thermo-stability. At $60 \mathrm{wt} \%$ PEI loading, the $\mathrm{CO}_{2}$ capacity reached 126 and $97.3 \mathrm{mg}-\mathrm{CO}_{2}$ per g-ads for PEI-10 000 and PEI-60 000, respectively, which are the highest ever reported. The PEI-modified adsorbents displayed superior thermo-stability with fully reversible $\mathrm{CO}_{2}$ adsorption as no appreciable changes were observed during the 50 cycle lifetime performance testing.

Relating the $\mathrm{CO}_{2}$ adsorption performance to the surface textural and morphological properties of the SCF materials reveals that the pore volume, pore diameter and window size of the SCF substrates collectively determine the $\mathrm{CO}_{2}$ uptake capacity of the PEI-modified adsorbents while for the macroand hybrid meso/macro SCFs, the morphology particularly the thickness of cell walls or framework silica struts also plays a vital role in facilitating higher levels of PEI impregnation with enhanced PEI mobility and accessibility for higher $\mathrm{CO}_{2}$ uptake capacities. Differing from previous findings, no particularly favourable pore diameters or window sizes for PEI impregnation are observed for the wide range of SCF materials examined, although close to linear relationships appear to exist between $\mathrm{CO}_{2}$ uptake capacity and total pore volume for the SCF materials with pore volumes lower than $2.2 \mathrm{~cm}^{3} \mathrm{~g}^{-1}$ and pore diameters/ window sizes below $28 \mathrm{~nm}$. 


\section{Conflicts of interest}

\section{Acknowledgements}

This work was supported by the Engineering and Physical Sciences Research Council [grant numbers EP/J020745/1, EP/ K000446/1, and EP/K000446/2], UK and the UK Carbon Capture and Storage Research Centre (EP/K000446/1, EP/K000446/2 and Call 2 Project C2-189). The authors also thank Dr Michael Fay for carrying out the FEG-TEM imaging measurements.

\section{Notes and references}

1 EIA, International Energy Outlook 2018 (IEO2018), US Energy Information Administration, Washington DC, 2018.

2 IEA, World Energy Outlook 2017, OECD/IEA, Paris, 2017.

3 Petroleum British, Energy Outlook 2018, BP stats, 2018.

4 S. E. Schwartz, Energy Environ. Sci., 2008, 1, 430-453.

5 M. Oschatz and M. Antonietti, Energy Environ. Sci., 2018, 11, 57-70.

6 F. Akhtar, L. Andersson, N. Keshavarzi and L. Bergström, Appl. Energy, 2012, 97, 289-296.

7 D. Bonenfant, M. Kharoune, P. Niquette, M. Mimeault and R. Hausler, Sci. Technol. Adv. Mater., 2008, 9, 013007.

8 K. Sim, N. Lee, J. Kim, E. B. Cho, C. Gunathilake and M. Jaroniec, ACS Appl. Mater. Interfaces, 2015, 7, 6792-6802. 9 J. Yu and S. S. Chuang, Energy Fuels, 2016, 30, 7579-7587.

10 X. Liu, Y. Sun, J. Liu, C. Sun, H. Liu, Q. Xue, E. Smith and C. Snape, ACS Appl. Mater. Interfaces, 2017, 9, 26826-26839.

11 J. Liu, N. Sun, C. Sun, H. Liu, C. Snape, K. Li, W. Wei and Y. Sun, Carbon, 2015, 94, 243-255.

12 Z. Bao, L. Yu, Q. Ren, X. Lu and S. Deng, J. Colloid Interface Sci., 2011, 353, 549-556.

13 X. Lv, L. Li, S. Tang, C. Wang and X. Zhao, Chem. Commun., 2014, 50, 6886-6889.

14 Y. Zeng, R. Zou and Y. Zhao, Adv. Mater., 2016, 28, 28552873.

15 H. Furukawa and O. M. Yaghi, J. Am. Chem. Soc., 2009, 131, 8875-8883.

16 F. Hillman, J. Brito and H. K. Jeong, ACS Appl. Mater. Interfaces, 2018, 10, 5586-5593.

17 E. V. Ramos-Fernández, A. Grau-Atienza, D. Farrusseng and S. Aguado, J. Mater. Chem. A, 2018, 6, 5598-5602.

18 G. Qi, Y. Wang, L. Estevez, X. Duan, N. Anako, A. H. A. Park, W. Li, C. W. Jones and E. P. Giannelis, Energy Environ. Sci., 2011, 4, 444-452.

19 W. Zhang, H. Liu, Y. Sun, J. Cakstins, C. Sun and C. E. Snape, Appl. Energy, 2016, 168, 394-405.

20 P. Bollini, S. A. Didas and C. W. Jones, J. Mater. Chem., 2011, 21, 15100.

21 S. Loganathan, M. Tikmani, A. Mishra and A. K. Ghoshal, Chem. Eng. J., 2016, 303, 89-99.

22 S. Loganathan and A. K. Ghoshal, Chem. Eng. J., 2017, 308, 827-839.
23 A. Zhao, A. Samanta, P. Sarkar and R. Gupta, Ind. Eng. Chem. Res., 2013, 52, 6480-6491.

24 J. H. Drese, S. Choi, R. P. Lively, W. J. Koros, D. J. Fauth, M. L. Gray and C. W. Jones, Adv. Funct. Mater., 2009, 19, 3821-3832.

25 F. Q. Liu, L. Wang, Z. G. Huang, C. Q. Li, W. Li, R. X. Li and W. H. Li, ACS Appl. Mater. Interfaces, 2014, 6, 43714381.

26 A. Goeppert, S. Meth, G. K. S. Prakash and G. A. Olah, Energy Environ. Sci., 2010, 3, 1949-1960.

27 S. Builes and L. F. Vega, Langmuir, 2012, 29, 199-206.

28 W. J. Son, J. S. Choi and W. S. Ahn, Microporous Mesoporous Mater., 2008, 113, 31-40.

29 B. Coasne, A. Galarneau, F. Di Renzo and R. J. Pellenq, Langmuir, 2006, 22, 11097-11105.

30 A. Heydari-Gorji, Y. Yang and A. Sayari, Energy Fuels, 2011, 25, 4206-4210.

31 K. Hori, T. Higuchi, Y. Aoki, M. Miyamoto, Y. Oumi, K. Yogo and S. Uemiya, Microporous Mesoporous Mater., 2017, 246, 158-165.

32 X. Wang, L. Chen and Q. Guo, Chem. Eng. J., 2015, 260, 573581.

33 E. S. Sanz-Pérez, A. Arencibia, G. Calleja and R. Sanz, Microporous Mesoporous Mater., 2018, 260, 235-244.

34 C. Chen, W. J. Son, K. S. You, J. W. Ahn and W. S. Ahn, Chem. Eng. J., 2010, 161, 46-52.

35 L. Zhou, J. Fan, G. Cui, X. Shang, Q. Tang, J. Wang and M. Fan, Green Chem., 2014, 16, 4009-4016.

36 X. Wang, X. Ma, C. Song, D. R. Locke, S. Siefert, R. E. Winans, J. Möllmer, M. Lange, A. Möller and R. Gläser, Microporous Mesoporous Mater., 2013, 169, 103-111.

37 C. H. Yu, C. H. Huang and C. S. Tan, Aerosol Air Qual. Res., 2012, 12, 745-769.

38 X. Yan, L. Zhang, Y. Zhang, K. Qiao, Z. Yan and S. Komarneni, Chem. Eng. J., 2011, 168, 918-924.

39 D. J. Subagyono, Z. Liang, G. P. Knowles and A. L. Chaffee, Chem. Eng. Res. Des., 2011, 89, 1647-1657.

40 D. J. Subagyono, M. Marshall, G. P. Knowles and A. L. Chaffee, Microporous Mesoporous Mater., 2014, 186, 84-93.

41 P. Schmidt-Winkel, W. W. Lukens, P. Yang, D. I. Margolese, J. S. Lettow, J. Y. Ying and G. D. Stucky, Chem. Mater., 2000, 12, 686-696.

42 X. Xu, C. Song, J. M. Andrésen, B. G. Miller and A. W. Scaroni, Microporous Mesoporous Mater., 2003, 62, 29-45.

43 W. W. Lukens, P. Schmidt-Winkel, D. Zhao, J. Feng and G. D. Stucky, Langmuir, 1999, 15, 5403-5409.

44 M. Sridhar, G. K. Reddy, N. Hu, A. Motahari, D. W. Schaefer, S. W. Thiel and P. G. Smirniotis, Microporous Mesoporous Mater., 2014, 190, 215-226.

45 R. van Grieken, J. A. Melero and G. Morales, Stud. Surf. Sci. Catal., 2002, 142, 1181-1188.

46 P. Schmidt-Winkel, W. W. Lukens, D. Zhao, P. Yang, B. F. Chmelka and G. D. Stucky, J. Am. Chem. Soc., 1999, 121, 254-255.

47 K. Li, J. Jiang, S. Tian, F. Yan and X. Chen, J. Mater. Chem. A, 2015, 3, 2166-2175. 
48 X. Ma, X. Wang and C. Song, J. Am. Chem. Soc., 2009, 131, 5777-5783.

49 M. A. Sakwa-Novak, S. Tan and C. W. Jones, ACS Appl. Mater. Interfaces, 2015, 7, 24748-24759.

50 J. C. Hicks, J. H. Drese, D. J. Fauth, M. L. Gray, G. Qi and C. W. Jones, J. Am. Chem. Soc., 2008, 130, 2902-2903.

51 E. E. Ünveren, B. Ö. Monkul, Ș. Sarıoğlan, N. Karademir and E. Alper, Petroleum, 2017, 3, 37-50.

52 V. Zeleňák, M. Badaničová, D. Halamová, J. Čejka, A. Zukal, N. Murafa and G. Goerigk, Chem. Eng. J., 2008, 144, 336-342.

53 J. Zhao, F. Simeon, Y. Wang, G. Luo and T. A. Hatton, RSC Adv., 2012, 2, 6509-6519.

54 R. Veneman, Z. S. Li, J. A. Hogendoorn, S. R. Kersten and D. W. F. Brilman, Chem. Eng. J., 2012, 207-208, 18-26.

55 M. B. Yue, L. B. Sun, Y. Cao, Y. Wang, Z. J. Wang and J. H. Zhu, Chem.-Eur. J., 2008, 14, 3442-3451.
56 C. M. Starkie, A. Amieiro-Fonseca, S. P. Rigby, T. C. Drage and E. H. Lester, Energy Procedia, 2014, 63, 2323-2330.

57 J. Wang, D. Long, H. Zhou, Q. Chen, X. Liu and L. Ling, Energy Environ. Sci., 2012, 5, 5742-5749.

58 X. Zhang, H. Qin, X. Zheng and W. Wu, Mater. Res. Bull., 2013, 48, 3981-3986.

59 D. S. Dao, H. Yamada and K. Yogo, Energy Fuels, 2015, 29, 985-992.

60 M. Ojeda, M. Mazaj, S. Garcia, J. Xuan, M. M. Maroto-Valer and N. Z. Logar, Energy Procedia, 2017, 114, 2252-2258.

61 R. Sanz, G. Calleja, A. Arencibia and E. S. Sanz-Pérez, J. Mater. Chem. A, 2013, 1, 1956-1962.

62 K. Li, J. Jiang, F. Yan, S. Tian and X. Chen, Appl. Energy, 2014, 136, 750-755.

63 W. Zhang, H. Liu, C. Sun, T. C. Drage and C. E. Snape, Chem. Eng. J., 2014, 251, 293-303. 